Portland State University

PDXScholar

7-1-2006

\title{
The Challenges International Students Face in Adjusting to Their New Status as Graduate Students: An Exploratory Case Study
}

Vincent Womujuni

Portland State University

Follow this and additional works at: https://pdxscholar.library.pdx.edu/open_access_etds

Part of the Curriculum and Instruction Commons, and the Educational Leadership Commons Let us know how access to this document benefits you.

Recommended Citation

Womujuni, Vincent, "The Challenges International Students Face in Adjusting to Their New Status as Graduate Students: An Exploratory Case Study" (2006). Dissertations and Theses. Paper 3972.

https://doi.org/10.15760/etd.5870

This Dissertation is brought to you for free and open access. It has been accepted for inclusion in Dissertations and Theses by an authorized administrator of PDXScholar. Please contact us if we can make this document more accessible: pdxscholar@pdx.edu. 


\section{THE CHALLENGES INTERNATIONAL STUDENTS FACE IN}

ADJUSTING TO THEIR NEW STATUS AS GRADUATE STUDENTS: AN

EXPLORATORY CASE STUDY

by

VINCENT WOMUJUNI

A dissertation submitted in partial fulfillment of the requirements for the degree of

DOCTOR OF EDUCATION in

EDUCATIONAL LEADERSHIP: ADMINISTRATION

Portland State University

2007 


\section{DISSERTATION APPROVAL}

The abstract and dissertation of Vincent Womujuni for the Doctor of Education in

Educational Leadership: Administration were presented July 18, 2006, and accepted by the dissertation committee and the doctoral program.

COMMITTEE APPROVALS:

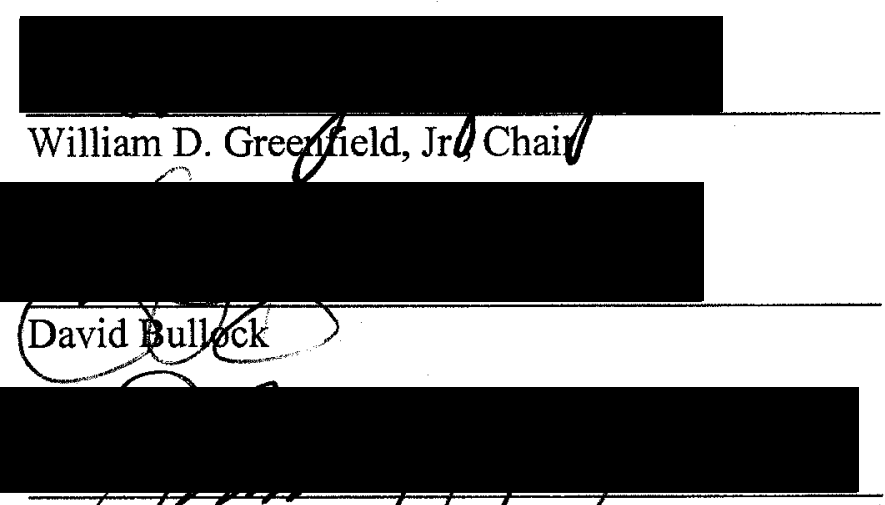

Sanuel D. Henry

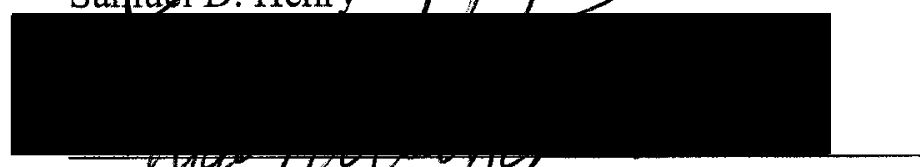

Magie McXlay L Znch

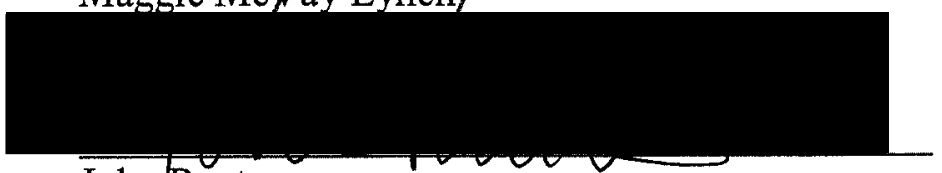

John Reuter

Representative of the Office of Graduate Studies

DOCTORAL PROGRAM APPROVAL

Carol L. Mack, Interim Dean

Graduate School of Education 


\begin{abstract}
An abstract of the dissertation of Vincent Womujuni for the Doctor of Education in Educational Leadership: Administration presented July 18, 2006.
\end{abstract}

Title: The Challenges International Students Face in Adjusting to their New Status as Graduate Students: An Exploratory Case Study

Over the last several years, the number of international students attending colleges and universities in the United States has increased substantially. While considerable time, effort, and university resources are often devoted to the recruitment of international students, it is unclear how well institutions are meeting the needs of these students. This growing number of international students requires foreign exchange professionals and university administrators to better understand the reasons why international students pursue higher education in the United States and the challenges they face.

This exploratory case study is to examine the challenges international graduate students encounter in adjusting to their new status as graduate students. Six research questions framed this study: What difficulties do international students face in their first year in graduate school? What adjustments do they need to make in their first year in graduate school? What challenges do continuing international graduate students face? In what ways are perspectives of continuing international graduate students similar to perspectives of beginning international graduate 
students? What university support resources do international graduate students say are helpful? What PSU support resources are needed, but missing?

The relevant literature addresses academic, social, psychological, cultural, financial, and housing adjustment challenges. The data for this research were collected by interviewing and surveying international graduate students at PSU. Data were analyzed using standard methods of qualitative data analysis.

Consistent with the results from other research, this study reveals the following adjustment challenges: unsatisfactory accommodation; inadequate financial resources; lack of culturally specific programs that are intentional, flexible and accessible; unfamiliarity with the new educational system; limited English proficiency; undeveloped infrastructure for on-going orientation; insufficient health services information; and unavailability of international student mentoring programs.

The findings of this study have the potential to inform both researchers and practitioners as institutions attempt to create sufficient international student support services. 


\section{ACKNOWLEDGMENTS}

Special thanks go to my major professor and chair of my doctoral committee, Dr. William Greenfield, for his guidance and constant support in this project. I also wish to thank the other committee members: Dr. Maggie McVay Lynch, Dr. Samuel Henry, and Dr. David Bullock, and Dr. John Reuter.

The faculty members, international education professionals, and PSU administrators involved in the education of international students deserve my thanks. Without their active participation this work would not have been possible.

Thanks also to my School of Education doctoral cohort. They were supportive throughout. What a great group of professionals!

To my deceased parents Ephraim and Florence Nyarwa, I will always be grateful to them for their encouragement and support. Thank you everyone! 
TABLE OF CONTENTS

PAGE

ACKNOWLEDGMENTS ...................................... i

LIST OF TABLES.......................................... v

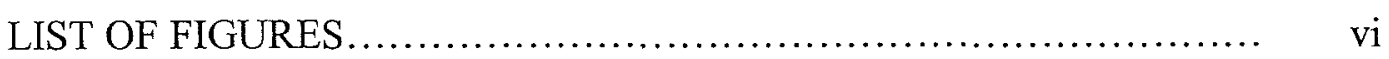

CHAPTER

I. INTRODUCTION.................................. 1

Rationale......................................... 3

Purpose.......................................... 4

Definition of Terms................................ 4

Research Questions.............................. 5

Summary ...................................... 6

II. REVIEW OF THE LITERATURE....................... 7

Academic and Social Adjustment Challenges........... 7

Psychological and Cultural Adjustment Challenges....... 10

Financial Adjustment Challenges.................. 11

Housing Adjustment Challenges ................... 15

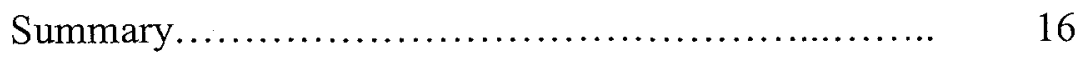

III. METHODOLOGY ..................................... 17

Overview, Goals, and Questions of the Study........... 17

Selection of Subjects for Interview............. 18

Considerations Leading to the Design of the Study....... 18 
ii

Interview Procedure............................. 19

Interviewing technique....................... 21

Data Collection Procedures......................... 22

Data Analysis Procedures........................... $\quad 24$

Role of the Researcher............................. $\quad 29$

Limitations....................................... 31

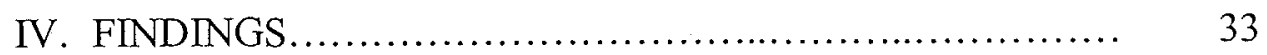

Results of Interviews........................... 33

Research Question $1 \ldots \ldots \ldots \ldots \ldots \ldots \ldots \ldots \ldots \ldots . \quad 34$

Individual Interview Item Responses and Analysis. 35

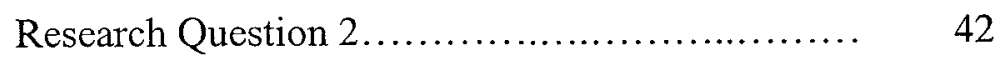

Research Question 3......................... $\quad 45$

Research Question $4 \ldots \ldots \ldots \ldots \ldots \ldots \ldots \ldots \ldots \ldots . \ldots \ldots$

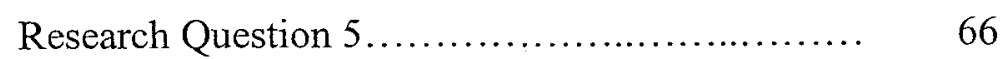

Research Question $6 \ldots \ldots \ldots \ldots \ldots \ldots \ldots \ldots \ldots . .68$

Results of Survey............................... $\quad 72$

Major Themes................................... $\quad 78$

Gap Between Students' Expectations and Reality. $\quad 79$

Issues and Concerns............................. 81

Misattribution.................................. 85

Academic Challenges.......................... 86

Social/cultural Challenges..................... 87 
Health/Psychological Challenges................. $\quad 89$

Financial Challenges........................... 90

Housing Challenges.......................... 90

V. PERSONAL REFLECTION ........................... 92

VI. STUDY IMPLICATIONS AND DISCUSSION ................ 101

Introduction.................................. 101

Implications for Professors......................... 101

Implications for Internationalization Action

Council and Diversity Action Council............... 103

Implication for International Affairs Counselors... 103

Implications for University Administration........ 103

Conclusion............................................ 105

REFERENCES ............................................ 107

APPENDICES

A. Survey Questionnaire.................................. 112

B. In-depth Interview Guide........................... 114

C. Informed Consent Form............................ 115

D. Focus Group Interview Protocol........................ 116

E. Pilot Interview Questions............................. 117 


\section{LIST OF TABLES}

TABLE

PAGE

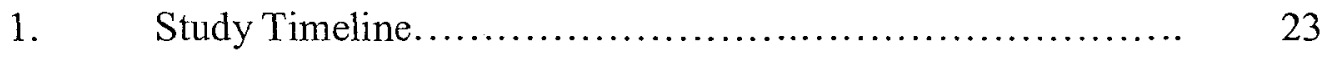

2. Data Triangulation................................... 27

3. In-depth Interview Participants........................ 35

4. Focus Group A: Beginning International Graduate Students... 50

5. Focus Group B: Continuing International Graduate Students... $\quad 50$

6. International Students' Adaptation Process.................. 52

7. Students' Expectations.................................. 54

8. Students' Graduate School Journey.......................... 56

9. Students' Adjustment Experiences........................ 57

10. Students' Adjustment Challenges......................... 59

11. Impact of Information on Students' Adjustment.............. 61

12. Students' Advice to the PSU Administration................... 63

13. Student Advice to Beginning International Graduate Students. 66 
LIST OF FIGURES

FIGURE

PAGE

1. Gender............................................ 73

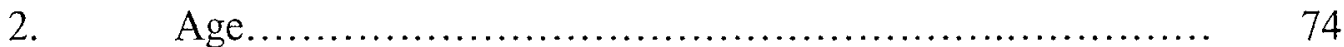

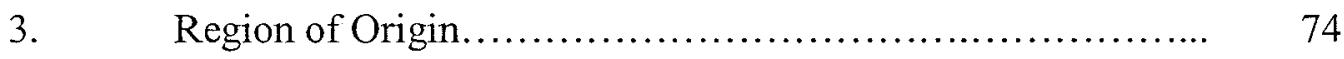

4. Marital Status........................................... 75

5. Academic Unit......................................... 76

6. Years of English.................................. 76

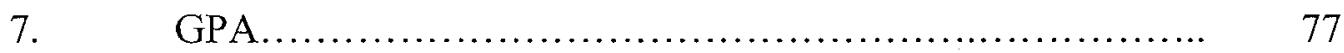


CHAPTER 1

\section{INTRODUCTION}

I had the following incident occur to me. During the data collection stage for my study, I went to one of the offices responsible for international students affairs at Portland State University (PSU) to seek information for this study. At the front desk, there was a receptionist answering phones and attending to students' needs. This man appeared rude to me and acted as though he did not have time for me. I asked him if I could see the Director of that office. He told me that the Director was not seeing students without appointments. Next, I requested to see one of the international students' counselors since it was during walk-in hours. I was told that no international student counselor was around, although the office of one of these counselors was open and the counselor was there.

I realized that this man was not only unwilling to help me, but also arrogant in the way he behaved toward me. I then introduced myself as a doctoral student doing a study on adjustment challenges of international graduate students and asked him if he had any orientation materials that could inform my study. The man said he did not have any such materials. I insisted that the information I was seeking should be at the front desk. The man angrily pulled out some materials and literally threw them on the desk in front of me.

At that point, one of the international student counselors walked out of her office to talk to this man at the front desk. I used this opportunity to address the 
counselor in person. She welcomed me into her office and was attentive to my issues. This incident is related here because it provides an excellent example of the struggles international students go through in adjusting to their new environment. It also reveals the lack of appropriate training for the staff members who interact with international students on a daily basis.

By deliberately refusing to give me the information I needed, did not this man know the sense of estrangement his behavior toward an international student could create in that student's mind and how this could hinder the student's ability to seek helpful information in the future? Based on this incident it is suprising that a staff member who is supposed to provide helpful information to international students is reluctant to do that.

This exploratory case study seeks to understand the challenges international students encounter in adjusting to their new status as graduate students at PSU. This report begins with the rationale and purpose of the study, and then discusses the definition of terms and the research questions. Following the introduction is a literature review, which describes international students' adjustment challenges. The methodology chapter describes the actual study and research procedures. This is followed by a report of the study results and a personal statement reflecting the researcher's graduate student experience. The report concludes with a chapter discussing the results, conclusions, and study recommendations. 
Rationale

The population of international students on U.S. campuses has rapidly increased over the last eight decades (Komiya \& Eells, 2001). In 1921-22 there were about 6,500 foreign students in institutions of higher learning in the United States (Cieslak, 1955). This number grew. The 30,462 college students from abroad studying in the United States in 1951-52 came from 126 countries, were enrolled in 1354 institutions, and constituted about $1 \%$ of the total number of students in colleges and universities (Cieslak, 1955). In 1968-1969, the number reported was 121,352 , or about 115,000 more than in 1921-22 (Clarke, 1970). Yi (2003) predict that the international student enrollment in U.S. colleges and universities will continue to increase in the future.

While the number of international students pursuing graduate studies in American universities has increased, it is curious that limited programs exist to help these students with their transitioning to graduate school life. According to Klinberg and Hull (1979), students from underdeveloped countries do not have sufficient command of the English language upon arrival in the United States to enable them to grasp the substance of the regular lectures in graduate courses. In addition, the cultural and educational backgrounds of international students present a real challenge for the university.

While PSU strives to address international students' adjustment challenges under the auspices of the general missions of the Internationalization Action Council and Diversity Action Council, limited resources make it difficult to 
achieve this goal. As a result, international students depend on a combination of friends, family, and outside organizations during transition to graduate school life.

For this reason, I have chosen to examine the stories of international graduate students as told through their own voices. It is hoped that by examining students' adjustment experiences, this study might shed light on both the challenges and opportunities that come from working with and helping these students adjust to their new life as graduate students.

\section{Purpose}

The purpose of this study is to explore the challenges international students face in adjusting to their new status as graduate students. Data were collected through in-depth interviews, focus groups, and surveys of international graduate students. Based on the literature, six areas of adjustment challenges were anticipated: academic, linguistic/social-cultural, interpersonal, financial, psychological, and practical (such as food, housing, and transportation). Researchers (Clarke, 1970; Cleslak, 1955; Du Bois, 1956) suggest that it is important to focus on these specific adjustment challenges because they play a major role in understanding the graduate school adjustment experiences of international students.

\section{Definition of Terms}

For the purpose of having a common language, the following definitions are used throughout this study. 
Case: For the purposes of this study, the case being studied is the nature of the international graduate students' adjustment challenges at PSU.

Case Study: A case study is an empirical inquiry that investigates a contemporary phenomenon within its real-life context, especially when the boundaries between phenomenon and context are not clearly evident (Yin, 1994, p. 13).

International Student: An international student is any person who currently resides or plans to reside in the United States on a non-immigration visa while studying at Portland State University. Most international students at PSU hold F-1 or J-1 student visas. U.S. citizens, permanent residents (green card holders), and persons with asylum or refugee status are not considered international students.

\section{Research Questions}

The research questions were derived from the pilot interviews with the Director of International Affairs and international graduate students, as well as from the literature review. The pilot interview revolved around specific questions: What services does the International Affairs Office provide to international graduate students? How effective are these services in helping international graduate students achieve overall success in the degree programs? How has the lack of English proficiency hindered students' adjustment? Is there any collaborative effort between the Office of International Affairs and other academic and administrative departments supporting international graduate students' orientation at PSU? What challenges do international graduate students encounter in 
transitioning to graduate school life? Are there any orientation programs specifically targeting international graduate students? What difficulties, if any, has the International Affairs Office encountered in getting international graduate students to participate in the general orientation programs offered by PSU? What has the office done to address those difficulties?

The researcher reviewed the literature to establish what the literature says about international graduate students' adjustment challenges. The researcher then used these pilot interview questions as a baseline for developing the following research questions:

1. What difficulties do international students face in their first year in graduate school?

2. What adjustments do they need to make in their first year in graduate school?

3. What challenges do continuing international graduate students face?

4. In what ways are perspectives of continuing international graduate students similar to perspectives of beginning international graduate students?

5. What university support resources are perceived as helpful?

6. What PSU support resources are needed, but missing?

\section{Summary}

This chapter provided an introduction to the background of the study along with the rationale, definition of terms, purpose of the study, and research questions. The next chapter presents a literature review. 
CHAPTER II

\section{REVIEW OF THE LITERATURE}

The literature informing this study draws on the more general literature addressing international students and includes studies of undergraduates as well as graduate students in order to capture a more comprehensive view of the international students' experiences. This is due to the limited number of studies focusing explicitly on international graduate students.

\section{Academic and Social Adjustment Challenges}

Lysgaard (1955) investigated the adjustment of 200 Norwegian Fulbright grantees who had received travel grants for various purposes and periods of time in the United States and who had returned to Norway by March 1953. He hypothesized that:

Adjustment as a process over time seems to follow a U-shape curve: adjustment is felt to be easy and successful to begin with; then follows a "crisis" in which one feels less well adjusted, somewhat lonely and unhappy; finally one begins to feel better adjusted again, becoming more integrated into the foreign community. Or, to put it differently, we suggested that adjustment as a process over time operates at increasingly more intimate levels of contact with community visited. The need for more intimate contact, however, makes itself known before one is able to achieve such contact and for some time, therefore, one may feel "lonely" and maladjusted.

Data contributing to this hypothesis came from interviews, averaging an hour and a half, with returning Fulbrighters in Oslo. Thus the adjustment curve was 
based upon the following breakdowns by duration of sojourn: (a) 6 months or less, (b) 6 to 18 months, and (c) more than 18 months. Lysgaard noticed, in reviewing the interviews, that the adjustment of those Fulbrighters who had been in the United States less than 6 months or more that 18 months tended to be "good." However, those who had been in the United States between 6 and 18 months seemed to have adjusted to the United States "less well."

Du Bois (1956) looks at adjustment as a process broken down into five phases: (a) the spectator (characterized by psychological detachment from the new experience); (b) the adaptive phase (characterized by active involvement in the problem of adjustment to the life of the host country); (c) the coming to terms phase (when the adaptive issues raised for the individual during the preceding phase are brought into an equilibrium); (d) the pre-departure phase (shortly before the individual leaves the host country); and (e) a readjustment phase ( a series of readjustments upon return to his home country).

Roxanna, Mark, and Ju (2000) investigated the academic and social issues of adjustment to American culture and higher education for undergraduate international students at the University of Tennessee. The survey study was conducted in order to determine which demographic, social, and academic factors might impede or facilitate adjustment to American higher educational life. Fiftyfour percent of the students came from South and East Asia; $23 \%$ from Western Europe and Canada; 13\% from Central and East Europe; 10\% from Central and South America. Thirty-six percent of the respondents felt confident with their English writing and reading skills. Thirty-three percent of the total 
indicated that they did not have any problems participating in class discussion and conversations in English. This study suggested that students from Europe and Canada adjusted better and had fewer problems and difficulties than did Asian and African students. It also found that Central Europeans appeared to have even fewer difficulties and problems than those who were from Western Europe and Canada.

Wang (2004) investigated the financial and emotional aspects of international students' experience in pursuing graduate education in the United States. A pool of 21 students was selected, with 3 from each of 7 departments, based on the best possible balance of gender, age, country of origin, and the length of stay in their program. The 21 international students consisted of 11 males and 10 females, from 23 to 34 years of age. They came from 11 countries: Bangladesh, China, Cyprus, India, Indonesia, Japan, Korea, Malaysia, Nigeria, Saudi Arabia, and Thailand. This study revealed that pursuing studies overseas was an immense undertaking in terms of the financial investment and emotional conflicts arising from academic pressures and the transition between cultures. The primary concern for students pivoted around academic study. This dimension of their experience could best be described as a series of challenges that were inextricably linked to the use of the English language. A majority of students reported varying degrees of difficulty or uneasiness and embarrassment with class activities that involved oral participation, especially at the beginning stage of their programs. Writing appeared to be the next biggest challenge. Reading difficulties encompassed both speed and comprehension. Wang (2004) concluded that the problem of language performance may not be accounted for by limited English proficiency alone, but may also include a 
constellation of social and cultural factors including perplexing guidance and administrative problems in connection with international students.

Psychological and Cultural Adjustment Challenges

Yi, Jun-Chih, and Yuko (2003) examined data provided by 562 self-identified international students who visited the counseling center at a major university in Texas over a six-year period (1992-1998). The international students were asked to complete questionnaires before their counseling appointments. Nearly 70 percent reported that they were extremely worried or somewhat worried about their future lives. It was found that due to the stigma of mental problems, international students were not likely to refer themselves for psychological help.

Dee and Henkin (1999) studied the challenges to adjustment to college life in the United States by Korean students at one Midwestern research university. Fiftytwo students participated in the study and completed a 47-item, self-report inventory. The majority of the respondents $(58 \%)$ were male. Forty-one percent were aged $27-31$. Others were 26 or less $(33 \%)$. A large majority $(79 \%)$ indicated that they did not have contact with other ethnic groups while growing up. Sixty-two of the respondents had never traveled abroad before coming to study in the United States. On the adjustment challenges, language was reported to be the most difficult problem encountered by respondents $(61 \%)$. Others $(18 \%)$ suggested that financial difficulties were most problematic. Adjustment to American culture was identified by $14 \%$ of the respondents as their most difficult adjustment problem. Initial periods of homesickness were extensive for many students. Fifty-one percent confirmed that they were homesick for the first three months or more of their stay. 
A large number of respondents (31\%) were unhappy, initially, when they arrived in the United States. The majority of the students (64\%) indicated that they currently or occasionally experience homesickness. Sixty-six percent of the respondents reported extensive social interaction with other Koreans. Only 11\% indicated extensive social interaction with American students. The majority $(67 \%)$ had no contact with American families in the community. The study found that gender, age, academic major, and previous exposure to foreign cultures were important variables in terms of Korean student adjustment.

\section{Financial Adjustment Challenges}

Financial difficulties are undoubtedly the most common and persistent problems that international students face during their stay in the United States. Cieslak (1955) identified the following factors affecting the financial status of a foreign student:

- The dollar shortage and the consequent limitations by foreign governments of dollar exchanges by students or their representatives;

- Incomplete and misleading budget information in college and university catalogues and bulletins;

- National emergencies and catastrophes;

- Inflation of foreign currencies;

- Inflation of the dollar;

- Family emergencies affecting the source of the student's funds; 
- Personal emergencies such as illnesses, unexpected travel needs, and delay in authorization of foreign exchange.

Other researchers (Cieslack, 1955; Day \& Hajj, 1986; Dillard \& Chisolm, 1983;

Lee, Abdella \& Burns, 1981; Manese, Sedlacek, \& Leong, 1988; Pedersen, 1991; Sakurako, 2000; Tinto, 1993) have advanced the following theories regarding factors affecting the financial status of international students:

- The sponsor and the student may hope that after arriving in the United States the student will be able to find some alternative way of financing his or her stay. This puts the student in a very precarious situation: a student cannot obtain an off-campus work permit during the first year, and there is no assurance of a permit after that (Cieslak, 1955).

- Students often discover that the university and the U.S. embassy are most concerned about the first year's funds. Students are supposed to show good evidence of the first year's financing and a reasonable expectation of funding after that. Unfortunately, some students, therefore, only worry about the first year and hope that something will come their way afterwards- - a scholarship, a work permit, or a new sponsor (Day \& Hajj, 1986).

- Students may also believe they can simply economize in the United States and get by on much less money (Dillard \& Chisolm, 1983).

- There may be some alternative sources of aid available, but the student has absolutely no certainty of obtaining funds from any of them (Dillard \& Chisolm, 1983). 
- Many students experience financial difficulties because the student had a scholarship to study in the United States but for any one of several reasons the scholarship is reduced or cancelled entirely (Lee et al.1981).

- Some students lose their sponsors due to death or because their sponsors have suffered a business reversal that affects the amount of money that can be sent to the student (Lee et al.1981).

- The student has become ill or has had an accident not entirely covered by medical insurance and has had to use money that was supposed to be used for tuition or living expenses to pay medical bills (Lee et al.1981).

- If students are supporting families_-wives, children, brothers and sisters at home- and have the opportunity to study in the United States, they may have to continue providing family support. Even if students have full sponsorship, it is very unrealistic to expect them to send money to their families. Scholarships and other forms of sponsorship are usually based on living costs, and students typically need all the funds to maintain themselves in the United States. If they try to send part of each month's stipend back home, they often experience a shortage of funds for their own living expenses. If students do not have a full sponsorship upon arrival, the resulting financial problems may be even greater (Manese, et al., 1988; Meloni, 1986).

- The student's own college or university may have some financial aid available, including part-time jobs, but the student must compete against all other students for any kind of aid (Pedersen, 1991). 
- Sometimes family circumstances change: a sibling is now entering a university and also needs financial support or a member of the family is ill and needs medical attention (Sakurako, 2000).

- If a student depends on one source of funds and something suddenly happens to that source, the student's entire life is affected: tuition due to the university, books needed for classes, warm clothing during winter months, rent, food, and transportation to and from school complicate their financial situations (Tinto, 1993).

- If the student comes to the United States without a sound financial base, he or she will feel financial pressure from the very beginning, and that can affect his or her academic work and overall psychological state from the first day (Tinto, 1993).

- The student may have underestimated the cost of education in an American university. The amount may be more than enough to live extremely well at home, leading students and sponsors to believe the students will never need so much money in the United States (Tinto, 1993).

- Students may have heard from other students that alternative sources of funding exist and thus may be lulled into thinking that financing an education after the first year will not present problems. For those students who do find new sources of funds, of course, this strategy works. However, it is very rare to find one source that will provide all necessary funds, and frequently students will come up with only partial funding after the first 
year. The gap between what is needed and what is available often causes considerable difficulty (Weill, 1982).

\section{Housing Adjustment Challenges}

International students must have satisfactory housing (Cieslak, 1955; Clarke and Ozawa, 1970; Du Bois, 1956). The older foreign students, as well as those who are married, are more likely to choose off-campus housing. Clarke and Ozawa, (1970) argue that the greatest potential for problems arises when there is the greatest dissimilarity of color or culture, whether housed in dormitories or in private housing. Cieslak (1955) found that not all international students reside in dormitories, even when dormitories are available to them. Types of housing reported by the 353 foreign students studied by Cieslak (1955) included university dormitories (223 students), rooms in private homes (45), housed with relatives or friends (39), private rooming houses (18), an international house (12), and the rest in other types of housing.

According to Pedersen (1991), many students do not have sufficient funds to afford adequate housing and to live where they want. International students who do not receive scholarships do not have adequate finances to live on campus (Manese, et al, 1988). Some students are allocated specific housing on campus, but campus housing is expensive and students prefer to live off campus where rent is affordable (Meloni, 1986). When students live off campus, they spend a lot of time traveling between home and the university and transportation time takes study time away from students. In addition, there is inconsistency of buses and trains, and the 
distances to travel between school and home create unnecessary stress (Dillard \& Chisolm, 1983).

\section{Summary}

This literature review addressed the academic, social, psychological, cultural, financial, and housing adjustment challenges of international students. As indicated earlier, much of the literature has centered on international undergraduate students and little on the international graduate students adjustment challenges in the United States. This lack of attention perhaps indicates that people in this country do not know much about the difference between international undergraduate students and international graduate students and what these two groups of international students aspire to achieve. The situation is lamentable and disturbs the common assertion that international graduate students represent an educational resource for the U.S. institutions of higher learning and leverage for faculty teaching and research work. The next chapter will address the methodology. 
CHAPTER III

\section{METHODOLOGY}

Overview, Goals, and Questions of the Study

Given that the focus of the study is international students' graduate school adjustment challenges, an exploratory case study research design, with its emphasis on the examination of one setting, was considered appropriate. The design of the study was based on three rationales. The first rationale for using this design was that the exploratory case study is analogous to a single experiment, and many of the same conditions that justify a single experiment also justify a case study (Stake, 1995; Yin, 1994). The second rationale for using this design is that a single case represents an extreme or unique case (Stake, 1995; Yin, 1994). The third rationale for using a case design was that the challenges of international graduate students present a revelatory case (Stake, 1995; Yin, 1994).

Yin (1994) argues that case studies require theory development, prior to the conduct of any data collection. He warns, however, that theory development should not be looked at from the theoretician's point of view, but from the view of propositional statements. This study was based on two propositions: (a) international graduate students succeed in adjusting to their new status as graduate students when foreign exchange professionals and university administrators worked together in a collaborative and cohesive manner; (a) over-reliance on a single office, 
the International Affairs Office, is not sufficient to meet the unique needs of international graduate students.

Selection of Subjects for Interview

The target population was international graduate students at Portland State University. Portland State University is home to more than 1,100 international students representing more than 79 foreign countries. According to PSU's view book, fall 2004 headcount revealed that international students comprised $5.6 \%$ of the PSU student body. Forty-three international graduate students participated in the study. Participants were selected with the help of the International Affairs Office that provided the researcher with the list of and contact information of these students. The office was also instrumental in forwarding invitation letter to potential participants in the study. All 43 students completed a survey. Out of the 43 participants, 5 beginning and 8 continuing international graduate students participated in focus groups A and B. Three students participated in individual interviews. Individual interview participants were identified by the researcher during the focus group interviews because the researcher felt that they were good candidates based upon the stories they shared. Only three individual interviews were conducted because it was difficult to schedule participants.

Considerations Leading to the Design of the Study

Consideration was initially given to a research design that would explore the perspectives of foreign exchange professionals, faculty, and administrators and 
compare their views with those of international graduate students, but because of limited time and resources, and knowing that investigation into cases may take time to complete, only international graduate students were selected to participate in the study. This meant that much of the data were drawn from the stories of international graduate students.

There were at least two basic problems to consider. First, because the researcher used a purposive sample of students, this meant that not only was the sample to a degree self-selecting, but also that it possibly was biased in favor of those students with strong opinions on adjustment challenges. Second, there was a possibility that students' perceptions would be a reflection of distorted memories as a result of their negative experiences. These factors, as much as possible, were taken into account.

Interview Procedure

In the fall 2005 two focus group interviews and three individual interviews were conducted. The purpose of the interviews was to listen and understand participants' graduate school adjustment challenges from their own voices. In each interview, I asked a series of pre-determined questions intended to stimulate discussion among group participants. The following eight pre-determined questions were asked in the focus group interviews.

1. Describe your journey in graduate school to this point. Was there any agency or association that helped you on your arrival in Portland?

2. What was the adjustment process like for you? 
3. Please tell me about any difficult, troublesome, or challenging situation that occurred to you on your arrival in the U.S. or at PSU.

4. Think about the first day of class. What are the most important things you needed to get/ listen to / watch for on day one?

5. How has the information you received or did not receive impacted you?

6. Suppose you were going to give advice to a beginning international graduate student who comes from the same background as you, what specific advice would you give this student?

7. Suppose you were going to give advice to PSU administration, what specific advice would you give?

8. Comments?

After focus group interviews, three individual interviews were conducted. The actual list of interviewees was obtained from the International Affairs Office and identified during the focus group discussions. The interview protocol was designed to elicit information on the students' own experiences. The following questions were used to guide the individual interview discussion:

1. What was the adjustment process like for you?

2. Think about the first day of class. What are the most important things you needed to get/listen to/watch for on day one? Describe your journey in graduate school to this point.

3. What do you see as key adjustment challenges of graduate school?

4. Please tell me about any difficult, troublesome, or challenging situation that occurred to you on your arrival in the U.S. or at PSU. 
5. What specific advice would you give to a beginning international graduate student?

6. How has the information you received or did not receive impacted you?

7. What specific advice would give to PSU administration?

During each interview, I compiled detailed notes as well as tape-recorded the students' responses. In this manner, I was able to generate, clarify, and adapt themes as I deemed appropriate. These themes then formed the backbone of my data analysis. While every comment made was important as far as informing the research questions was concerned, I selected quotes that I felt best captured the students' adjustment challenges.

Interviewing technique

Interviewing is commonly used and considered one of the best techniques to utilize when conducting case studies of a few selected participants. McCracken (1988) stresses that the individual qualitative interview should not be used in isolation because the realities it reports are not the only realities with which the interviewer must contend. Yin (1994) suggests that focus group interviews also can be useful in instances where the respondents may be more forthcoming with the added safety or stimulus of a group.

The benefit of interaction with the investigator allows for clarification of responses and further probing when warranted (Stake, 1995). Morgan (1993) relates that interviewing is a research technique in which the researcher determines the focus, and the data comes from the group interaction. Krueger and Casey (2000) 
also argue that the interview process is necessary when one can not observe behavior, feelings, or how people interpret the world around them. For this reason, I chose to interview participants because I felt that by listening to their stories from their own voices would give me a better understanding of their graduate school adjustment challenges.

\section{Data Collection Procedures}

Initially, I conducted pilot interview with the Director of International Education Services at Portland State, as well as with a few international graduate students. The pilot interviews were intended to determine the research questions. The pilot interview revolved around specific questions: What services does the International Affairs Office to international graduate students? How effective are these services in helping international graduate students achieve overall success in the degree programs? How has the students' educational background hindered smooth adjustment to their new learning environment? Is there any collaborative effort between the Office of International Affairs and other academic and administrative departments supporting international graduate students' orientation at PSU? What challenges do international graduate students encounter in transitioning to graduate school life? Are there orientation programs specifically targeting international graduate students? What difficulties, if any, has the International Affairs Office encountered in getting international graduate students to participate in the general orientation programs offered by PSU? What has the office done to address those difficulties? 
Once these questions had been answered, I met with my academic adviser to discuss the varying stages of the project, delineate appropriate interview questions, identify participants, develop protocols for approaching potential interviewees, and discuss strategies for facilitating interviews.

Table 1

Study Timeline

\begin{tabular}{|l|l|l|l|}
\hline \multicolumn{5}{|c|}{ Fall Term August October } \\
\hline $1^{\text {st }}$ interview & & $9 / 2005$ & \\
\hline $2^{\text {nd }}$ interview & & $9 / 2005$ & \\
\hline $3^{\text {rd }}$ interview & & $9 / 2005$ & \\
\hline Focus groups & & & \\
\hline Group 1 & $8 / 2005$ & & \\
\hline Group 2 & $8 / 2005$ & & \\
\hline Surveys & $8 / 2005$ & & \\
\hline Documents & $8 / 2005$ & $9 / 2005$ & $10 / 2005$ \\
\hline
\end{tabular}

In the fall of 2005, I started collecting data (see Table 1). First, two focus group interviews were conducted. The focus groups were followed by three individual interviews. From focus group and individual interviews a survey instrument was developed, modified, and administered to 60 international graduate students at PSU, with a $75 \%$ rate of return. 
Data Analysis Procedures

The analysis of data was guided by the purpose of the study (Bogdan and Biklen, 1992). I remained open to making adjustments but stayed on track by continually assessing if data collection and analysis were answering the research questions. Since I was conducting individual and group interviews with similar participants, results from the first focus group suggested improvements for the second focus group (Goetz \& LeCompte, 1984). When I had important realizations during the focus group interviews, I wrote them down as soon as possible. If one or two participants disagreed with the rest of the group, I probed to understand why. After each focus group, I devoted some time to identify themes, quotes, surprising comments, similarities and differences, and anything that needed to be changed or added regarding any questions. I also paid attention to nonverbal information which could not be fully captured in the transcripts.

After I had completed the two focus group interviews, I thought it would be helpful to review the literature again to note central issues in the literature topics that might have been neglected. I was able to code responses into categories to enable me to organize the data to reveal patterns that would be difficult to detect by just listening to a tape or reading a transcript. I always kept original copies of my transcripts. First, I compared the focus group transcripts for the two groups (beginning and continuing international graduate students). I numbered lines of the transcripts, so as to know where specific responses came from. I carefully reviewed my data at least twice during long, undisturbed periods. 
I conducted initial coding by generating numerous categorical themes as I read responses, labeling data that were related. I wrote notes to myself, listened to and diagrammed relationships I noticed, and watched for special terms that respondents used because they often indicated an important topic. Initial coding was followed by focused coding (Lofland \& Lofland, 1995). During focused coding, I tried to subdivide coding categories, and looked for repeating ideas and larger themes. Repeating ideas were the same ideas expressed by different respondents, while themes were larger topics that were organized or connected a group of repeating ideas.

During data coding and analysis, the following questions remained at the back of my mind: What common themes emerge in responses about specific research questions? How do these patterns help to illuminate the broader study questions? Are there deviations from these patterns? If so, are there any factors that might explain these deviations? How are participants' new learning environments or past experiences related to their behavior and attitudes? What interesting stories emerged from the responses? How do the stories help illuminate the central study questions? Do any of these patterns suggest that additional data may be needed? Do any of the key study questions need to be revised? Are the patterns that emerge similar to the findings of other studies on the same topic? If not, what might explain these discrepancies?

Realizing that interpreting qualitative data can be subjective, I tried to verify my conclusions. I reviewed my data repeatedly to check that my conclusions were grounded in what actually was said. I made sure that I was voicing the views of 
participants rather than my own. I also triangulated by using evidence from the survey to verify my conclusions. To improve the study's validity I showed my results to three of the focus group participants and asked them if I had accurately recorded what they said and meant. The point of data saturation was reached when no new information or concepts emerged from the data. Table 2 illustrates how data from interviews and survey were triangulated. 
Table 2

Data Triangulation

\begin{tabular}{|c|c|c|c|}
\hline & \multicolumn{3}{|c|}{ Study Data Source } \\
\hline $\begin{array}{c}\text { Study Research } \\
\text { Questions }\end{array}$ & $\begin{array}{l}\text { Individual } \\
\text { Interviews }\end{array}$ & $\begin{array}{l}\text { Focus Group } \\
\text { Interviews }\end{array}$ & $\begin{array}{c}\text { Survey } \\
1-11 \text { demographic } \\
\text { data, } 12-24 \text { general } \\
\text { questions }\end{array}$ \\
\hline $\begin{array}{l}\text { 1. What } \\
\text { difficulties do } \\
\text { international } \\
\text { students face in } \\
\text { their first year } \\
\text { in graduate } \\
\text { school? }\end{array}$ & $\begin{array}{l}\text { 1. Tell me about } \\
\text { the orientation } \\
\text { you received } \\
\text { on your arrival } \\
\text { at PSU. What } \\
\text { was your being } \\
\text { in a new } \\
\text { environment } \\
\text { like for you? }\end{array}$ & $\begin{array}{l}\text { 1. What was the } \\
\text { adjustment } \\
\text { process like } \\
\text { for you? }\end{array}$ & $\begin{array}{l}\text { 11. I learned about } \\
\text { PSU from sources } \\
\text { other than from } \\
\text { PSU. } \\
\text { 12. Overall, my } \\
\text { housing facilities } \\
\text { are adequate for } \\
\text { my needs } \\
\text { 13. In general I have } \\
\text { been received on } \\
\text { equal terms by } \\
\text { American } \\
\text { classmates. } \\
\text { 14. In general I think I } \\
\text { have been well } \\
\text { received by } \\
\text { people on campus. }\end{array}$ \\
\hline $\begin{array}{l}\text { 2. What } \\
\text { adjustments do } \\
\text { they need to } \\
\text { make in their } \\
\text { first year in } \\
\text { graduate } \\
\text { school? }\end{array}$ & $\begin{array}{l}\text { 2. Describe your } \\
\text { journey in } \\
\text { graduate } \\
\text { school to this } \\
\text { point. How } \\
\text { long have you } \\
\text { been at PSU? } \\
\text { What is your } \\
\text { subject major } \\
\text { area? }\end{array}$ & $\begin{array}{l}\text { 2. Think about } \\
\text { the first day } \\
\text { of class. } \\
\text { What are the } \\
\text { most } \\
\text { important } \\
\text { things you } \\
\text { needed to } \\
\text { get/ listen to / } \\
\text { watch for on } \\
\text { day one? }\end{array}$ & $\begin{array}{l}\text { 15. The information I } \\
\text { received during } \\
\text { orientation was } \\
\text { sufficient for my } \\
\text { needs } \\
\text { 16. In general, my } \\
\text { health condition is } \\
\text { good } \\
\text { 17. I participate in } \\
\text { religious and other } \\
\text { non-academic } \\
\text { activities. }\end{array}$ \\
\hline
\end{tabular}


Table 2

Data Triangulation (continued)

\begin{tabular}{|c|c|c|c|}
\hline $\begin{array}{l}\text { Study Research } \\
\text { Questions }\end{array}$ & $\begin{array}{l}\text { Individual } \\
\text { Interviews }\end{array}$ & $\begin{array}{l}\text { Focus } \\
\text { Group } \\
\text { Interviews }\end{array}$ & $\begin{array}{l}\text { Survey } \\
1-11 \text { demographic } \\
\text { data, 12-24 general } \\
\text { questions }\end{array}$ \\
\hline $\begin{array}{l}\text { 3. What challenges } \\
\text { do continuing } \\
\text { international } \\
\text { students face? }\end{array}$ & $\begin{array}{l}\text { 3. What do you } \\
\text { see as key } \\
\text { adjustment } \\
\text { challenges of } \\
\text { graduate } \\
\text { school? } \\
\text { 4.How has the } \\
\text { information } \\
\text { you received or } \\
\text { did not receive } \\
\text { impacted you? }\end{array}$ & $\begin{array}{l}\text { 3.Describe your } \\
\text { journey in } \\
\text { graduate } \\
\text { school to this } \\
\text { point. } \\
\text { 4. What do you } \\
\text { see as key } \\
\text { adjustment } \\
\text { challenges of } \\
\text { graduate } \\
\text { school? }\end{array}$ & $\begin{array}{l}\text { 18. English language } \\
\text { was a part of my } \\
\text { secondary or } \\
\text { college study. } \\
\text { 19. I acquired my } \\
\text { conversational } \\
\text { skills through } \\
\text { school. } \\
\text { 20. My conversational } \\
\text { skills are good } \\
\text { enough to } \\
\text { understand } \\
\text { professors' } \\
\text { lectures and } \\
\text { instructions. }\end{array}$ \\
\hline $\begin{array}{l}\text { 4. In what ways are } \\
\text { perspectives of } \\
\text { continuing } \\
\text { international } \\
\text { graduate students } \\
\text { similar to those of } \\
\text { the first year } \\
\text { international } \\
\text { graduate students? }\end{array}$ & $\begin{array}{l}\text { 5.Tell me a story } \\
\text { about one } \\
\text { stressful } \\
\text { adjustment } \\
\text { challenge you } \\
\text { encountered at } \\
\text { PSU? }\end{array}$ & $\begin{array}{l}\text { 5.Please tell me } \\
\text { about any } \\
\text { difficult, } \\
\text { troublesome, or } \\
\text { challenging } \\
\text { situation that } \\
\text { occurred to you } \\
\text { on your arrival } \\
\text { in the US or at } \\
\text { PSU. }\end{array}$ & $\begin{array}{l}\text { 21. There was an } \\
\text { official agency that } \\
\text { aided me on my } \\
\text { arrival in Portland. }\end{array}$ \\
\hline
\end{tabular}


Table 2

Data Triangulation (continued)

\begin{tabular}{|c|c|c|c|}
\hline $\begin{array}{l}\text { Study Research } \\
\text { Questions }\end{array}$ & $\begin{array}{l}\text { Individual } \\
\text { Interviews }\end{array}$ & $\begin{array}{l}\text { Focus Group } \\
\text { Interviews }\end{array}$ & $\begin{array}{l}\text { Survey } \\
1-11 \\
\text { demographic } \\
\text { data, 12-24 } \\
\text { general questions }\end{array}$ \\
\hline $\begin{array}{l}\text { 5. What university } \\
\text { support } \\
\text { resources are } \\
\text { perceived as } \\
\text { helpful? }\end{array}$ & $\begin{array}{l}\text { 6. What do you } \\
\text { think is a } \\
\text { better way to } \\
\text { assist foreign } \\
\text { students to } \\
\text { achieve } \\
\text { overall } \\
\text { success at } \\
\text { PSU? }\end{array}$ & $\begin{array}{l}\text { 3. What specific } \\
\text { advice would } \\
\text { you give to a } \\
\text { beginning } \\
\text { international } \\
\text { graduate } \\
\text { student? }\end{array}$ & $\begin{array}{l}\text { 22. I feel that I } \\
\text { have sufficient } \\
\text { time to do my } \\
\text { study and my } \\
\text { class } \\
\text { assignments. }\end{array}$ \\
\hline $\begin{array}{l}\text { 6. What PSU } \\
\text { support } \\
\text { resources are } \\
\text { needed, but } \\
\text { perceived as } \\
\text { missing? }\end{array}$ & $\begin{array}{l}\text { 7. What } \\
\text { information } \\
\text { did you need } \\
\text { on day one of } \\
\text { class? }\end{array}$ & $\begin{array}{l}\text { 4. How has the } \\
\text { information you } \\
\text { received or did } \\
\text { not receive } \\
\text { impacted you? } \\
\text { 5. What specific } \\
\text { advice would } \\
\text { give to PSU } \\
\text { administration? }\end{array}$ & $\begin{array}{l}\text { 23. I feel that the } \\
\text { financial aid I } \\
\text { received is } \\
\text { sufficient for } \\
\text { my needs. } \\
\text { 24. I have other } \\
\text { sources of } \\
\text { financial aid in } \\
\text { addition to } \\
\text { scholarship. }\end{array}$ \\
\hline
\end{tabular}

Role of the Researcher

My role as a researcher was to position myself as a learner in the research process. McCracken (1988) stresses the importance of viewing the investigator as a kind of instrument. Due to the need of the researcher to use his experience and imagination to fashion a match for the patterns revealed in the data, it is thought that the self of the researcher is considered a "bundle of templates to which data can be held up against until parallels emerge" (p. 19). While the researcher as an 
instrument tool works most easily when the respondent's ideas match those of the researcher, the process can also work when the researcher imaginatively constructs the meaning of the subject's ideas.

The personal characteristics, knowledge, and practical experience of a researcher in any study that utilizes an interview method of data collection can exert a tremendous amount of influence on the study and its results (Agar, 1980; Yin, 1994). As an international graduate student at Portland State University, the researcher had empathy for participants in this study. Throughout his research, the researcher tried to capitalize on the benefits his experience as an international student provided him, while still trying to maintain a stranger's point of view, so as to identify the unusual or distinctive features of each particular setting, informant, or interview.

McCracken (1988) stresses that the individual qualitative interview should not be used in isolation because the realities it reports are not the only realities with which the interviewer must contend. In this study, it was critical to have the researcher become a part of the team and actively participate in the study. The perceptions of the researcher were an important part of the study and influenced the outcome since data were being interpreted by him. In this exploratory case study, the researcher was intimately connected with the case being studied and learned more from the experience. Being part of the natural setting allowed the researcher to better understand the associations and connections between ideas and themes in the data. 
Throughout the course of the study, the researcher built relationships and connections with participants. The researcher paid special attention to the events, group norms, mundane details, and contextual aspects that influence the study. As a complete participant, the researcher was actively involved in the study. The researcher spent time journaling after each focus group and interview session to reflect upon and interpret the students' reports of their experiences, and to capture his own reflections on and responses to these data.

\section{Limitations}

There were four limitations to consider when interpreting the results of data obtained from surveys and interviews. First, the students were predominantly international graduate students, so it was possible for the idiosyncratic nature of their experience to impact their individual feelings, attitudes, and perceptions about their adjustment challenges.

Second, the study relied on data from a single institution - Portland State University. But the fact that the researcher followed the proper research methodology, the results of the study can be applied broadly to other institutions dealing with international graduate students.

Third, disadvantages of survey methods, which include difficulty of developing a valid and reliable survey instrument (questionnaire design), limits to the in-depth detail of data collected with surveys, lack of control over timeliness of responses, potential low response rates, difficulties in determining if respondents 
are responding truthfully, and possible misinterpretation of data results and/or inappropriate use of data analysis procedures could affect the results of the study.

Four, failure to establishing validity could be a limitation. In order to establish validity of the results, the researcher used multiple sources of evidence including surveys, interviews, and documents. Also, the researcher shared the findings of the study with the participants in order to insure the study was accurate and complete from their perspective. 


\section{CHAPTER IV}

\section{FINDINGS}

Results of Interviews

This study was conducted at Portland State University. According to PSU's fall 2004 view book, enrollment, excluding extension students, was 17,241 (12,246 FTE), including 12,598 undergraduate students (9,135 FTE), and 4,643 graduate students $(3,111 \mathrm{FTE})$. Sixty-one percent $(7,664)$ of undergraduate students and $38 \%$ $(1,751)$ of graduate students were enrolled full time. Fifty-five percent of undergraduate students and $60 \%$ of graduate students were female. Six percent of students pay out-of-state tuition. Eighteen percent of undergraduate students and $11 \%$ of graduate students are members of protected minority groups.

Overall, $16 \%$ of PSU students who are citizens or permanent residents of the U.S. are members of protected minority groups (8.6 percent are Asian, 2.8\% African-American, 3.7\% Hispanic, and 1.1\% Native American). An additional $5.6 \%$ of the student body is international students, representing 79 nations. This study focused on a selected population that is part of the $5.6 \%$ of the international student body. The remainder of this chapter will concentrate upon the findings from the following six research questions:

1. What difficulties do international students face in their first year in graduate school?

2. What adjustments do they need to make in their first year in graduate school?

3. What challenges do continuing international students face? 
4. In what ways are perspectives of continuing international graduate students similar to perspectives of continuing international graduate students?

5. What university support resources are perceived as helpful?

6. What PSU support resources are needed, but missing?

\section{Research Question 1}

What difficulties do international students face in their first year in graduate school?

In fall 2005, this researcher conducted three individual interviews with three international graduate students. The students were identified and selected during focus group interviews. The criteria for student selection included the following: (a) targeted international students who have been in the graduate school for less that one academic year; (b) targeted international students who have been in graduate school for more than one academic year; (c) targeted students who have experienced graduate school adjustment challenges; and (d) students who have good stories to tell. Two of the participants were continuing and one was a beginning international graduate student (see Table 3). 
Table 3

In-depth Interview Participants

\begin{tabular}{|c|c|c|l|l|}
\hline Student & Nationality & Year & \multicolumn{1}{|c|}{ School/College } & \multicolumn{1}{|c|}{ Gender } \\
\hline 1. & Japan & Continuing & Education & Female \\
\hline 2. & Ghana & Beginning & $\begin{array}{l}\text { Liberal Arts and } \\
\text { Sciences }\end{array}$ & Male \\
\hline 3. & India & Continuing & Engineering & Male \\
\hline
\end{tabular}

Individual Interview Item Responses and Analysis

In order to better understand the international graduate students' adjustment challenges, interviewees were asked to comment on their graduate school adjustment challenges. Students' responses were edited for brevity and clarity.

Questions 1 and 2: Tell me about the orientation you received on your arrival at PSU. What was being in a new environment like for you? How has your adjustment to graduate school at PSU been?

Student/Consultant 1: I arrived through summer of 2004, so I did not have any opportunity for orientation. If I had had an orientation, I would have adjusted much faster and understood the situation well before carrying on to classroom. I had to go to class looking very green. Later on, the International Education Services Office tried to enlighten us, but they did not give us the information we needed. The most frustrating area was that because we are not given orientation, if we are faced with a problem we do not know whom to go to for help. I think the university should do much in the direction of helping international students with helpful information during orientation.

Student/Consultant 2: In my first year I did not have enough information. I don't think I did. I just started without information. I just jumped in. I expected to get information on books. My question was how can I get my books? Although the people at the book store tried to help me, still, it was challenging for me to talk to the book store people because my English was not good. I also wanted to ask more specific questions such as assignments: How many quizzes? How many writing 
papers do we have in a term? What kind of final exams do we have? - many, many details.

Student/Consultant 3: I expected them to tell me how many hours I can work because at PSU there is a different system. I think orientation at PSU is mainly about main buildings like Cramer Hall, Neuberger Hall, Peter Stott, Smith Center, and things like that. I wish they could help us know more during the orientation. It was difficult for me to adjust to the weather conditions in my first semester - it was really cold. Emotional support obviously is lacking here because we don't have family here - it is very difficult. All we have are friends we just met.

Question 3: What do you see as key adjustment challenges of graduate school?

Student/Consultant 1: We need a lot of orientation as far as accommodation is concerned. That is the first issue of concern for any international student. Before you can make any meaningful learning, you should have a place to put you head. The system they have in America is different from what we have in Africa. In Africa when you are admitted to any university, you know that you are going to have an accommodation. Halls of residences are not managed by any entity that is not part of the institution. Everything is fused into the tuition. When you pay tuition, you know that accommodation is no longer a headache, but finding affordable accommodation here is extremely difficult. When I received my admission letter, I understood the requirements from the stand point of the African education system. Of course I never had credit history! How did the university expect me to find accommodation without help? I was lucky I found a student to accommodate me temporarily until I found my own place. This was a student I just met from school who was not an African student, so we constantly had cultural problems and also problems of trying to understand each other.

I seriously had problems paying rent-seriously. In Africa, we pay our rent at the end of the month, but here I realized that you have to pay the rent at the beginning of the month. And then as soon as you fail to pay your rent, you are evicted and nobody is willing to bail you out. You have to go around searching for the money and it becomes a headache. Instead of thinking about studies, you are thinking about where to get money to pay rent. The issue of rent now becomes a major problem because you start looking for funds for the next rent and for the next month.

Also, academic adjustment has been quite difficult, especially in my program because of my unfamiliarity with the American education system. When I came here the biggest problem I had was computer. We had computers in our schools, in Ghana, but we had no teachers or technicians to teach us. We had a small computer lab, which was not enough to accommodate hundreds of students at the university, so, getting a chance to use a computer was next to impossible.

When I came to PSU, I started with the computer right from beginning, but I did not have skills in typing. I knew how to check my e-mail, but that was all I knew about computers. At home, I usually drafted the letters and gave them to the 
secretary to type them for me. But when I got here, I had to type my school papers myself, which made it difficult for me to complete my assignments on time. Having experienced difficulty with computer, I approached my professor and told him that I could not type fast enough to complete my assignments on time and requested him to allow me to write my assignments in ink. The first time the professor accepted, but later he said that he wanted my assignments typed. It sometimes took me two to three days to type an essay. Sometimes I had to stay over-night to do my homework - it was very challenging. I had to buy a CD to practice typing and started learning from the beginning. The problem was not about my learning the computer; the problem was that I did not have anybody to mentor me and to help me with my computer skills.

Food is one such challenging area. I'm still going through the same challenge right now because the first kind of food I was able to get used to was pizza. The way I had to adjust was to start preparing my own dish because it was very hard for me to get used to the food that was being served in restaurants and in food stores.

I also encountered financial challenges. Before I came to America I was a teacher and I also had another job in Ghana. The money I had saved sustained me for three terms, but at the end of my third semester, I ran out of my savings and my financial situation went from bad to worse. I did not expect to get a scholarship from my government or from PSU since I was not a U.S. citizen. When my financial situation worsened, I applied for financial hardship status. After acquiring work authorization, I encountered yet another challenge. The jobs that were available for me were night jobs. It was very hard to work at night and attend classes during the day. Sometimes I would be dozing in class because I came to class tired. I applied for the International Cultural Exchange Scholarship, but the chances of getting the scholarship were slim. Besides, the scholarship is just a onetime scholarship of $\$ 1,000$. Further still, the scholarship is awarded on a quota basis. At the time of my applying, the African continent had exhausted its quota. It was difficult for me to stay for months and months without a job. My bills were piling up. You can imagine leaving your good job and coming to begin like a student. It is very challenging.

Student/Consultant 2: security was a major concern for me. I came here by myself. When I got here, I started imagining that something dangerous might happen to me, or somebody might break into the apartment. The feeling of insecurity I had bothered me. There are other things I wanted to know. For instance, I wanted to know where the garbage, electricity, and water were. In my second year, my accommodation situation changed. Initially, I was living by myself, but eventually, I started living with my Japanese friend. Sharing a room with my Japanese native did not help me improve my English because we would always speak in Japanese. Also, because I was a graduate student and my roommate was an undergraduate, we continually had conflicts. My roommate enjoyed making noise and having fun, but I liked to concentrate on my studies. I would expend a lot of energy in solving conflicts rather than on my school work. 
Another challenge I encountered was physical health. Usually in Japan we can just go to see a doctor without appointment, but here I did not know that we have to make an appointment to see a primary doctor. One day I had a health condition and I went directly to the hospital without going to see the doctor at PSU and they charged me a lot of money because I did not know the system. Even though I participated in international student orientation, I really did not remember many things after the orientation. Maybe they gave us the information, but I did not know the system--primary doctor. I also did not know how to adjust to the weather. I did not know that it rains a lot in Portland. I did not know what the right or normal room temperatures or outside normal temperatures were. I knew how to take care of myself, but I did not know how to adjust when I got cold and when I got sick. Also, stress caused me stomachache. I also developed eye problems and then ear infections. I had to find stores that sold Japanese food because I could not adjust to the America food.

I also encountered financial difficulties. Although I have a teaching assistantship, monthly stipend, and some financial help from home, money is still not enough. The applications for scholarships and grants usually go around during the term, but I really don't have time to write that statement to apply for the scholarship. It is also hard to get that information. I know that money is available to apply for scholarships, but there are many regulations that hinder international students from applying. Also, we need help to complete scholarship applications. Sometimes we don't even know how to write the statements they ask for. I know there is help at Career Center, but it would be nice for the International Affairs Office to provide students with sample writings for the application list so that students can know what kinds of financial assistance are available for international student.

Student/Consultant 3: One of the challenges I face was accommodation. There is too little space available in PSU's campus housing. It is even more difficult for students who arrive after the fall quarter to find accommodation. All the halls of residence are filled regardless. So they should try to build more housing facilities.

Question 4 and 5: What information did you need on day one of class? How has the information you received or did not receive impacted you?

Student/Consultant 1: My first day in class was challenging. Basically, I expected something quite similar to my country. I realized that the facilities here are great, but the area of human relations is lacking. I was lucky I met an American lady who was very helpful to me. This lady educated me about the American education system. She tried to give me an insight into American culture, and I started learning right from there.

Student/Consultant 2: On my first day of class, I wanted the professors to remember my name and face. I wanted to get attention from them. I wanted to know if he or she is a nice person. I wanted to know whether they are intercultural 
sensitive or if they don't care about it. I would say that the American education system is student-centered/orientation compared to Japanese educational system. Students always speak up and talk a lot and sometimes challenge professors. Professors expect international students to participate like other domestic students, but it is an unrealistic expectation because students have just arrived and most of them can not express themselves well in English. I needed information about programs that can help improve my English. I needed a mentor. I needed academic and career counseling, financial information, and information on accommodation.

Student/Consultant 3: On my first day of class I was a little bit worried about what would be the expectations of the instructors. I did not know the instructors. I did not know which instructor was an easy grader and which instructor was a tough grader. I was expecting to get a mentor who would teach me the ropes. I wanted a former graduate student. I wanted to hear the professors' expectations from a student perspective, rather than from an advisor perspective. I was worried much about keeping a $\mathrm{B}$ average to avoid academic probation. I think my worry is the same worry that every international student has. I really think that each department can come up with a network of graduate students who can host a free lunch and a day-long meeting or kind of seminar or kind of a get-together for the new students. Such gatherings can help both international students and domestic students get to know one another. This would also be an opportunity for international students to get information on job and career opportunities. It was very difficult to find a continuing international graduate student to mentor me and to guide me on the right course of academic decisions.

Question 6: Tell me a story about one stressful experience at PSU?

Student/Consultant 1: I was not familiar with the grading system. I did not like the way the professor took time to return my assignments. When I presented my final papers the professor never told me about my performance and I came up with the grade of C. I thought that the professor did not completely understand the situation of international student. He did not understand why international students really should be treated differently from an American student. I felt that they should have that understanding because we are here for such a short time, which makes it hard for us to understand everything that goes on here. I tried to talk to my advisor about the professor, but my academic advisor told me to forget about it. That was the only professor who gave me hard time, but I have met other professors who are good and nice who understand problems of international students.

Student/Consultant 2: I encountered one disturbing experience with one professor. I just sent him and e-mail saying "I just have a request for you," the professor was offended by my statement. He called me into his office and told me that I could have said I wanted a favor from him not a question. I thought that was a cultural misunderstanding because I did not see anything wrong with my statement. 
I asked myself, "is it because I am an Asian woman, or is it because I ' $m$ Japanese?" I started to think many things. I wanted to participate more in my graduate program, but sometimes it was difficult for me because I felt I wasn't invited to speak. I felt that the professors were not paying attention to me. This made me think that they didn't like me. Also, I thought that they didn't want to listen to the Japanese issue because they are interested in American domestic education only. I just started to believe that they did not want me to participate in the class, so I just kept quiet. But the more I kept quiet the more I started thinking that the professor may think I was dense and that is why I was not participating in class. I had another disturbing experience with a domestic student. One day we were planning a group discussion and one of my group members said to me, "you are an Asian woman you don't have to speak during the group discussions. You can be quiet." I could not believe it! I asked myself, "is she serious?" Politely, I told her that in this country you have to speak, otherwise you can not get credit, but she insisted that it was okay for me not to speak and not to contribute in my group.

Student/Consultant 3: I had a misunderstanding with one of my instructors when I took my first class. I sent him an email asking him a different question, but the professor took it in a different way and said that I was not supposed to write him such an email. This made me nervous because I did not know the right way to communicate with my professor if he misunderstood every message I asked him. Then I had to schedule a meeting with this professor. In the meeting, the professor acknowledged that there was nothing wrong with my email and told me that everything was okay. Although the situation was resolved, it created mistrust between the professor and me and it was very difficult for me trust him anymore and to go to him for help for the fear of being misunderstood.

Question 7: What do you think is a better way to assist foreign students to overcome their adjustment challenges?

Student/Consultant 1: Academic advising. Academic advisors should be close to students. Academic advising should not be so professional. Advisors should put themselves into students' shoes and understand students' problem. In the departmental meetings, there should be discussions about how to deal with diversity in class and how to help foreign students cope with their new academic environment. Professors need to be realistic. Some professors should slow down when they are teaching a class so that students can understand what they are saying. International students should be allowed to work more than 20 hours a week so that they can get enough money to be able to pay their bills. I understand that the basic reason we are here is because of studies, but if a student is able to maintain the required GPA, he/she should be allowed to seek off-campus employment. The university administration needs to understand that not all international students come from wealthy families. There needs to be a program in place to help needy students with financial assistance. 
Student/Consultant 3: I would ask those responsible for international students' orientation to show not only the PSU buildings, but also help international students to figure out where to deposit the money, where to buy food, how to acquire affordable accommodation, and how to prepare for graduate school. They could also arrange tours to different places of students' interests. I think one thing that really "sucks" is that an international student is required to work only a certain number of hours and also on-campus hours. I talk to many people in different universities and they kind of mention that it is the government policy that all international students are required to work only 20 hours a week. My question is, if a student is doing well, why should he or she be restricted to working only 20 hours a week. I understand that the GPA has to be maintained at 3.0. If somebody is getting a GPA of 3.5 and could work more and earn more and at the same time the institution should let that student work.

Question 8: Comments?

Student/Consultant 1: My overall experience is that even though PSU has opened its doors to international students, I think they need to understand the culture of international students. They also need to do more to ease the pressure on the international students, especially the graduate students-I can see that they are not doing much. They are only interested in collecting their money and not interested in the welfare of international students. My advice is that apart from international student counselors, the International Education Services Office and the University administration can develop a peer mentoring program and an office that can work as an information clearing house, where students can meet mentors and peers, especially the senior international students and the well-trained mentors to provide on-going orientation in academic and non-academic fields. This will help the newly arrived students and those who need specialized and on-going assistance to cope with and adjust to their new learning environment. They should think of getting an office if possible, or think of getting international students a hall of residence. They should subsidize the financial situation, even though we are expected to pay everything. Because the challenges of international students are so enormous, the university should put in place programs that provide international students with access to financial options and opportunities available on and offcampus. International students should be allowed to take some summers off so that they can work and save enough for other terms. I know they are following the federal law, but I think if they want to encourage international students to come and study in America, they need to start to address this problem.

Work is the biggest problem. The university board should try to find work placement for international students. In as much as we are here for academic purposes, we should have work experience and the university should help us move toward that direction. We are not going to stay here for life, so they should help us for two-three years so that we can have the American work experience to be able to help our people back home. 
My advice to an international student is determination. It is very tough for international students. Students should forget their fantasies about America because life here is not as luxuries as they think. Once they get here, they must be determined to work hard in every aspect of their life. In terms of information, the first thing is, this is an advanced system and the information is right on internet. So, I would advise them to try to get their student account set-up so that they can have access to the school web site and seek information that is related to their individual needs. Students also need to understand that foreign students are not eligible for financial aid apart from maybe a scholarship and teaching assistantships. It depends on luck, so keep trying.

Student/Consultant 2: I think I need more inclusion in the graduate program. Domestic students giving orientation are so busy, they don't have time to take care of other students and sometimes they become really competitive. As an international student, it is really hard to also be competitive as much as they are because of the limited English. I always felt I was kind of left out. I need more inclusion and also attention. I wish I had more attention from students and from faculty. Some faculty members are very nice to me and care about me but some of them are not, so communication between professor and student is really important even if they are really busy. Probably the international student office may have that kind of information. I would advise international students to get more specific information from their department, always to find a mentor, somebody who can find that information for you.

Student/Consultant 3: I also think that International graduate students are more at a disadvantage compared to undergraduate international students. The university has many programs geared toward helping international undergraduate students and none for international graduate students. I think Portland State University should do a better job of reaching out to international graduate students and working toward devising programs to help students cope with their new status as graduate students.

\section{Research Question 2}

What adjustments do they need to make in their first year in graduate school?

Like continuing international graduate students, beginning international graduate students are more mature than undergraduate international students. Most of them have worked in their native countries before, and a big majority support themselves financially. They feel lonely and need support in numerous domains, and the university can only fulfill a certain number of their needs. 
The individual interview participants were overwhelmingly in agreement about the adjustments they needed to make in their first year in graduate school. The adjustment most often mentioned related to housing, due to students not being familiar with the process of renting (security deposit, lease and rental agreement, credit history) and high cost of rent.

Students mentioned a need for adjustments to American English.

In my first class, I wanted to listen attentively because I was worried that I would have a hard time understand the America accent. I found out that my class was being taught by a Chinese professor, whose accent was totally different. I had to strain myself very hard to understand what he was saying. I had to adjust to his way of speaking if I had to pass his class.

Another area where students needed adjustment was weather. Students felt that the weather was too cold compared to the weather of their home countries. One student said, "Weather affected my life. I don't know how people survive that. I was almost dying. It is hard adjusting to the weather of Oregon."

Students also said that they need to adjust to the American culture. One student commented:

It is culturally inappropriate to debate a professor in my country. I noticed here in my class that American students are not afraid to have a casual conversation and sometimes argue with professors in class. I also noticed that students bring food in class and eat while the professor is lecturing. Some students even hang their legs on the desk. In my country, students are supposed to respect professors. We don't eat in class and don't hang legs on the desk. It was a culture shock for me to see students behaving that way. 
Another area that students mentioned was food. Students felt that in their first day in the U.S. they had a hard time adjusting to the American food. Students are still new to the area and they don't know their way to stores that sell food from their home country. One student said, "Adjusting to food was a big challenge for me. Since I did not know my way around, I did not know where to buy food from my country."

A need to adjust to the academic environment was clearly evident in the focus group data. One student from India commented:

The higher education system in America is totally different. In my country, the university sets the syllabus for particular courses, and exams are conducted by the university and graded by the university; the instructor only teaches the course. But when I came here, I found that the instructor himself or herself develops the syllabus, teaches, and grades, which means that professors have complete autonomy regarding what goes on in class.

Students also tend to worry about achieving their academic goals in order to graduate. One student had this to say about his academic adjustment challenges:

Academic adjustment has been quite difficult, especially in my program because of my unfamiliarity with the American education system. When I came here the biggest problem I had was computer. We had computers in our schools, in Ghana, but we had no teachers or technicians to teach us. We had a small computer lab, which was not enough to accommodate hundreds of students at the university; so, getting a chance to use a computer was next to impossible. In addition, in order to have access to a computer you had to pay at internet cafes. When I came to PSU, I started with the computer right from beginning, but I did not have skills in typing. I knew how to check my e-mail. That was all I knew about computers. At home I usually drafted the letters and gave them to the secretary to type them for me. But when I got here, I had to type my school papers myself, which made it difficult for me to complete my assignments on time. 
Having experienced difficulty with computer, I approached the professor and told him that I could not type fast enough to complete my assignments on time and requested him to allow me to write my assignments in ink. Initially, the professor accepted, but later he said that he wanted my assignments typed. It sometimes took me two to three days to type an assay. Sometimes I had to stay over night to do my homework--it was very challenging. I had to buy a CD to practice typing and started learning from the beginning. The problem was not about my learning the computer; the problem was that I did not have anybody to mentor me and to help me with my computer skills.

It is clear from the focus group and individual interview data that beginning international students are in need of assistance in figuring out how to get from the airport to campus, finding appropriate accommodation, finding classes on their first day, making sense of the American university system and learning how to interact with faculty, administration and fellow students.

\section{Research Question 3}

What challenges do continuing international students face?

One of the most often mentioned adjustment challenge was housing. International students can hardly be expected to find satisfactory housing without aid. For their welfare, they must have appropriate housing. Many students do not have a credit history and yet they have to be subjected to the credit background check. This makes it hard for students to find affordable accommodation.

It was also found that the university has housing facilities available for international students, but these facilities are more expensive and students prefer to live off-campus. Some of the often mentioned problems connected with housing by 
participants included, high rent, uncaring host families, problems with roommates, lack of knowledge of what is appropriate and affordable, and complex rental application process. Data from surveys reveal the majority of the students (77\%) are not satisfied with their housing facilities.

Financial difficulties were found among participants. Students said that lack of financial information prior to their arrival made it difficult for them to budget adequately for their stay in the U.S. One continuing international graduate student commented:

Before I came to America I was a teacher and I also had another job in my home country. The money I had saved sustained me for three terms, but at the end of my third semester, I ran out of my savings and my financial situation went from bad to worse. I did not expect to get a scholarship from my government or from PSU since I was not a U.S. citizen. When my financial situation worsened, I applied for financial hardship status.

Students said that their financial difficulties were complicated by restrictive immigration rules and regulations. For instance, international students cannot work for more than 20 hours a week. Also, students said that the complicated process for applying for scholarship puts international students at a disadvantage because of their inability to answer the statement of need in a sophisticated language as per the application requirements. Although students acknowledged that they have graduate assistantships and teaching assistantship, monthly stipend, and some financial help from home, still the money is not enough for their needs. 
Time was also expressed as an impediment to adjustment. The participants said that they didn't have time to apply for the scholarship. Also, students thought that no information or assistance was available for them to complete the applications.

Another challenge that continuing international graduate students mentioned involved academic adjustment. There was an agreement among students that academic adjustment has been quite difficult. This has been due in part to students' unfamiliarity with the American education system.

One student mentioned that security was her major concern. "When I got here, I started imagining that something dangerous might happen to me, or somebody might break into the apartment. The feeling of insecurity I had bothered me."

Another challenge that students mentioned involved health. Students expressed their unfamiliarity with the health insurance system and the American health system. Even though students received some information from the International Affairs Office, students felt that it was difficult to remember all the information at the time because they were busy settling down. One continuing student commented:

Usually in Japan we can just go to see a doctor without an appointment, but here I did not know that we have to make an appointment to see a primary doctor. One day I had a health condition and I went directly to the hospital without going to see the doctor at PSU and they charged me a lot of money because I did not know the system. I really did not remember many things after the orientation. Maybe they gave us the information, but I did not know the system-primary doctor. I also did not know how to adjust to the weather. I did not know that it rains a lot in Portland. I did not know what the right or normal room temperatures or outside normal temperatures were. I knew how to take care of myself, but I did not know how to adjust when I got cold and when I got sick. Also, stress 
caused me stomachache. I also developed eye problems and then ear infections.

Another challenge mentioned by interview participants involved meeting professors' expectations. The unfamiliarity with the new grading system kept students in constant fear of losing their graduate status. The fear of losing status often put students into conflict with professors because students felt that they should be treated differently than the domestic students.

\section{Research Question 4}

In what ways are perspectives of continuing international graduate students similar to perspectives of beginning international graduate students?

Thirteen international graduate students were selected to participate in focus group interviews. The criteria for their selection were developed by the researcher as follows:

- minimum of one semester of graduate school

- knowledge of and experience of adjustment challenges

- fulltime international graduate students holding a F-1 or J-1 visa

- willing to participate in the study

The selection process took approximately 2 months of telephone calls, e-mails, and personal contacts. The thirteen students participated in focus group A and focus group B. Focus group A was composed of five beginning international graduate 
students and focus group B was composed of eight continuing graduate students (see Tables 4 \& 5).

To establish the base line for understanding the adjustment challenges and to give direction for the study, focus group participants were asked eight questions regarding their adjustment challenges. The questions asked were as follows:

1. What was the adjustment process like for you?

2. Think about the first day of class. What are the most important things you needed to get/ listen to / watch for on day one?

3. Describe your journey in graduate school to this point.

4. What do you see as key adjustment challenges of graduate school?

5. Please tell me about any difficult, troublesome, or challenging situation that occurred to you on your arrival in the U.S. or at PSU.

6. What specific advice would you give to a beginning international graduate student?

7. How has the information you received or did not receive impacted you?

8. What specific advice would give to PSU administration? 
Table 4

Focus Group A: Beginning International Students

\begin{tabular}{|c|c|c|c|c|c|c|c|c|c|}
\hline & $\frac{\bar{d}}{0}$ & 8 & $\frac{8}{3}$ & $\begin{array}{l}\frac{\pi}{3} \\
\frac{\vec{E}}{\pi} \\
\frac{5}{0} \\
\frac{1}{\pi}\end{array}$ & 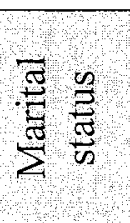 & $\frac{\vec{\sigma}}{\vec{\pi}}$ & $\begin{array}{l}4 \\
0 \\
5 \\
5 \\
\frac{5}{6} \\
0 \\
* 1\end{array}$ & 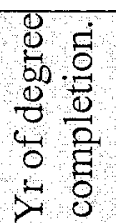 & $\stackrel{\&}{b}$ \\
\hline 1. & Male & 26 & Asia & 2004 & Single & English & 1 & 2007 & 3.1 \\
\hline 2. & $\begin{array}{c}\text { Fem } \\
\text { ale }\end{array}$ & 26 & Africa & 2005 & Single & Chem. & 6 & 2008 & $\begin{array}{c}3.4 \\
7\end{array}$ \\
\hline 3. & $\begin{array}{c}\text { Fem } \\
\text { ale }\end{array}$ & 38 & Asia & 2005 & Single & Ed. & 3 & 2009 & 3.6 \\
\hline 4. & Male & 38 & $\begin{array}{c}\text { Middle } \\
\text { East }\end{array}$ & 2004 & Single & CEI & 3 & 2008 & $\begin{array}{c}3.2 \\
9\end{array}$ \\
\hline 5. & $\begin{array}{c}\text { Fem } \\
\text { ale }\end{array}$ & 27 & Europe & 2005 & Single & Bio & 8 & 2010 & 3.2 \\
\hline
\end{tabular}

Table 5

Focus Group B: Continuing International Graduate Students

\begin{tabular}{|c|c|c|c|c|c|c|c|c|c|}
\hline & 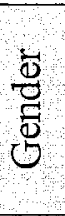 & $\frac{8}{4}$ & $\frac{\theta}{0}$ & $\frac{\sum_{E}^{\pi}}{\frac{\pi}{6}}$ & $\sum_{\vec{E}}^{E} \frac{n}{E}$ & 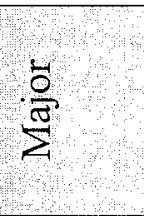 & 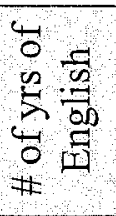 & 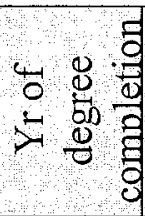 & $\frac{4}{0}$ \\
\hline 1. & $\bar{M}$ & 27 & Africa & 2003 & $\bar{S}$ & Chem. & 3 & 2008 & 3.75 \\
\hline 2. & $\mathrm{~F}$ & 38 & M.E & 2000 & $S$ & Eng. & 4 & 2007 & 3.1 \\
\hline 3. & $\mathrm{M}$ & 28 & Asia & 2003 & $\mathrm{~S}$ & Math. & 4 & 2007 & 3.5 \\
\hline 4. & $\bar{M}$ & 24 & Europe & 2003 & $S$ & $\mathrm{PA}$ & 4 & 2009 & 3 \\
\hline 5. & $\bar{M}$ & 32 & Africa & 2002 & $S$ & SO & 7 & 2008 & 3.1 \\
\hline 6. & $\mathrm{~F}$ & 29 & Asia & 2002 & $\mathrm{~S}$ & Eng. & 8 & 2007 & 3 \\
\hline 7. & $\mathrm{M}$ & 31 & ASIA & 2002 & $\mathrm{~S}$ & MATH & 3 & 2006 & 3.1 \\
\hline 8. & $\mathrm{~F}$ & 27 & Africa & 2003 & $S$ & PA & 11 & 2007 & 3.41 \\
\hline
\end{tabular}


Focus group responses were audio taped, transcribed from audiotapes and edited for purposes of clarity and brevity. In this manner, I was able to generate, clarify, and adapt themes as I deemed appropriate. These themes then formed the backbone of my focus group data analysis. Each literal or paraphrased comment by focus group participants was placed in tables, along with themes and group type. While every comment made was important as far as informing the research questions was concerned, I selected quotes that I felt best captured the students' adjustment challenges (see Tables 6-13).

Focus Group Question 1: What was the adjustment process like for you?

Table 6 relates students' responses on their adjustment process. Based upon their responses, the adjustment process can best be described in terms of loneliness, difficulties of learning to socialize with domestic students, difficulties of learning to be a student again, difficulty of adjusting to the American English and foreign professors' accents, difficulty in understanding American currency, complicated housing and rental application process, difficulties of adjusting to the classroom environment, culture shock, and difficulty in adjusting to food, weather, and professors' expectations. 
Table 6

International Students' Adaptation Process

\section{Themes Group Type Student Responses}

Loneliness Beginning I didn't have any orientation. I was just there on campus asking myself "where am I supposed to go?" Nobody was there to help me. I don't know how I got through the first days.

Domestic Continuing American students speak so fast that it is hard Students to follow what they are saying. I'm still having a hard time understanding students in my class. Sometimes I got so frustrated that I started speaking French without noticing.

Difficulties of Continuing Learning to be Student It was very difficult adjusting, especially for a Student Again me because I had worked for about seven years, so it was hard for me to go back to school and learn English after a long time out of school.

$\begin{array}{ll}\text { American } & \text { Beginning } \\ \text { English and } & \\ \text { Foreign } & \\ \text { Professors } & \\ & \\ \begin{array}{l}\text { Housing and } \\ \text { Host Family }\end{array} & \\ \text { Professors' } & \text { Continuing } \\ \text { Expectations } & \end{array}$

I found out that my class was being taught by a Chinese professor, whose accent was totally different. I had to strain myself very hard to understand what he was saying. It was very frustrating.

The most helpful orientation I received was from the FOCUS group.
The challenge I encountered was figuring out professors' expectations. One professor has more stress on mathematical concepts, while another professor says you are not mathematics major that you should concentrate on engineering concepts. I had to learn to get what was good from professors and leave what I thought was not beneficial to me. 
Table 6

International Students' Adaptation Process (continued)

$\begin{array}{lcc}\begin{array}{l}\text { Themes } \\ \text { Discomfort } \\ \text { with Class }\end{array} & \begin{array}{c}\text { Group Type } \\ \text { Environment }\end{array} & \begin{array}{l}\text { Student Responses } \\ \text { I felt discomfort in class because my } \\ \text { classmates pretended not to understand what I } \\ \text { was saying. They wanted me to say one thing } \\ \text { twenty times. It made me feel uncomfortable. }\end{array} \\ \begin{array}{l}\text { Learning to } \\ \text { Find }\end{array} & \text { Continuing } & \begin{array}{l}\text { I learned to find information on my own. If I } \\ \text { wanted to read something I would go to the } \\ \text { library or go on line and look for whatever } \\ \text { information I needed. I didn't want to bother } \\ \text { professors. }\end{array}\end{array}$

Focus Group Question 2: Think about the first day of class. What are the most important things you needed to get/ listen to / watch for on day one?

Table 7 presents students' perspectives on their experiences on their first day of class. Data from the focus group indicate that students come to class with high expectations. Students expected to get professors and classmates' attention and details of their course requirements. The majority of the students said that their expectations on their first day of class were not met because of the challenges they encountered. These challenges included inability to understand professors' accents, isolation from domestic students, language barrier, different education system, and cultural misunderstanding with students and professors. 
Table 7

Students' Expectations

Themes Group Type $\quad$ Student Responses

Student Beginning As an international student I expected more than

Expectations what the professor provided: more caring and more attention. I know there are many international students and professors don't have time for each student, but at least I expected attention from professors.

Communication Beginning

My first class was challenging. The professor was literally singing. He was talking so fast that it was extremely difficult to follow his lectures. Before I came to America, I had to listen to tapes of lectures in English to familiarize myself with the American English. Because I was only used to tapes, it was difficult to follow a professor who talked that fast. At one point I felt like stopping him, telling him to slow down. It was very difficult to capture the content of his lecture because of his talking so fast.

Isolation Beginning

On the first day of class, I realized that we Student international students were isolated from the American students. Sometimes we had to really fight to be part of the group. You feel you want to beg students to be your friends so that they can show you the way around. You see many international students trying to drag their bags looking lost because there is nobody to pick them up at the airport. 
Table 7

Students' Expectations (continued)

\begin{tabular}{|c|c|c|}
\hline Themes & Student Type & Student Responses \\
\hline Language & Continuing & I was sometimes disappointed. I felt as though \\
\hline Disability & student & $\begin{array}{l}\text { I had a disability because I could not speak } \\
\text { English clearly. I had to study very hard to } \\
\text { improve my communication skills. }\end{array}$ \\
\hline $\begin{array}{l}\text { Faculty } \\
\text { Autonomy }\end{array}$ & Continuing & $\begin{array}{l}\text { In my country, the university sets the syllabus } \\
\text { for particular courses, and exams are } \\
\text { conducted by the university and graded by the } \\
\text { university; the instructor only teaches the } \\
\text { course. But when I came here, I found that the } \\
\text { instructor himself or herself develops the } \\
\text { syllabus, teaches, and grades, which means } \\
\text { that professors have complete autonomy } \\
\text { regarding what goes on in class. }\end{array}$ \\
\hline $\begin{array}{l}\text { Cultural } \\
\text { Sensitivity }\end{array}$ & Beginning & $\begin{array}{l}\text { Sometimes I felt that some professors are not } \\
\text { culturally sensitive. I would expect professors } \\
\text { to spend as much time with students as } \\
\text { possible, going over the lecture or the } \\
\text { questions in more detail. I know professors } \\
\text { don't have training in that area, but cultural } \\
\text { sensitively should be part of the professors' } \\
\text { training. }\end{array}$ \\
\hline $\begin{array}{l}\text { Colloquial } \\
\text { Language }\end{array}$ & Beginning & $\begin{array}{l}\text { Sometimes professors make jokes and talk } \\
\text { about homework assignment using American } \\
\text { expressions that I'm not familiar with. Once } \\
\text { in a while I would miss important } \\
\text { communication because it was said as a joke. } \\
\text { Sometimes I would not turn in my assignment } \\
\text { not because I did not study, but because the } \\
\text { assignment was given as a joke. }\end{array}$ \\
\hline
\end{tabular}

Focus Group Question 3: Describe your graduate school journey to this point. Was there any agency or association that helped you on your arrival in Portland? 
Table 8 presents students perspectives on their graduate school journey. Data reveals many adjustment challenges along the way_-from safety, to lack of appropriate correspondence prior to their arrival, to failure of the university to arrange airport pick up, to lack of appropriate information on arrival, and to problems with the English language.

Table 8

Students' Graduate School Journey

\begin{tabular}{|c|c|c|}
\hline Theme & Student Type & Student Responses \\
\hline Safety & Continuing & $\begin{array}{l}\text { My parents were worried about my safety } \\
\text { when I came to the U.S. because it was after } \\
\text { the September } 11,2003 \text {. }\end{array}$ \\
\hline $\begin{array}{l}\text { Communication } \\
\text { Through } \\
\text { Gestures }\end{array}$ & Continuing & $\begin{array}{l}\text { The only way I could communicate was } \\
\text { through gestures because I did not speak } \\
\text { English when I came to PSU. I also met other } \\
\text { international students who were having } \\
\text { problems with the language, so we were } \\
\text { hanging out in downtown, but we couldn't } \\
\text { talk to each other-just sign language. }\end{array}$ \\
\hline $\begin{array}{l}\text { Learning the } \\
\text { Language Out } \\
\text { of Necessity }\end{array}$ & Continuing & $\begin{array}{l}\text { I was pretty much forced to learn my English. } \\
\text { I think that staying with the host family really } \\
\text { helped me improve my English. }\end{array}$ \\
\hline $\begin{array}{l}\text { Language } \\
\text { Barrier }\end{array}$ & Beginning & $\begin{array}{l}\text { I wanted to socialize and to get to know other } \\
\text { international students. Most of the students I } \\
\text { wanted to make friends with did not speak } \\
\text { English either, so we had a hard time } \\
\text { communicating with each other. }\end{array}$ \\
\hline
\end{tabular}

In-depth Interview Question 3: Please tell me about any difficult, troublesome, or challenging situation that occurred to you at PSU. 
Table 9 presents students perspectives on students' troublesome and challenging situations. The difficult, troublesome, or challenging situations that students mentioned included mostly misunderstandings with professors, classmates and roommates. Misunderstandings with professors involved students' feeling that professors were prejudiced and failure of professors to pay attention to students' struggles with the language.

Table 9

Students' Adjustment Experiences

\section{Theme Student Category $\quad$ Student Responses}

Bad Experience Continuing I had a troubling experience with with Roommates roommates. I wanted to share a room with American students so that I could improve my English. The first roommate was an older woman, who whined and complained exceedingly about her passed life. She was very protective of the phone. She always thought that I was going to make long distance telephone calls to my family in Africa. I tried to live with a freshman roommate, but she liked partying and having fun, and I liked to concentrate on my studies. We could not get a long, I had to move again.

Teaching Continuing I encountered a challenging experience Assistantship during my teaching assistantship duties. Challenges Although I believed I was a very good mathematician, it was very difficult to talk and explain to students mathematical concepts in English. 
Table 9

Student's Adjustment Experiences (continued)

Theme Student Category

Insufficient

Information on

Housing and

High Cost of

Rent

Continuing

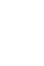

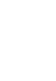

Anger and

Frustration
Beginning
Student Responses

\begin{abstract}
When I came to Portland, I rented my apartment over the internet because I did not get housing information from PSU. I found a small one-bedroom apartment- - the smallest one bedroom apartment I have ever seen. I felt embarrassed whenever my friends came over to visit me because the bathroom was in the living room. Besides, the apartment was very expensive. I paid $\$ 490$ in monthly rent. Since I had already signed the lease, I was forced to stay in that apartment for a year before I moved to a better apartment. Because I did not get information on the implications of lease and rental agreement, I did not know that if you sign the lease you cannot break it. Obviously the lease has a lot of legal jargons that are even hard for an average American to understand.
\end{abstract}

I was angry and frustrated at myself because I could not effectively participate in class.

Focus Group Question 4: What do you see as adjustment challenges of graduate school?

Table 10 presents students perspectives on adjustment challenges of graduate school. As noted earlier, challenges often mentioned include housing, academic, financial, and social adjustment challenges. 
Table 10

Students' Adjustment Challenges

$\begin{array}{cc}\text { Themes } & \text { Group } \\ \text { Type } & \text { Student Responses }\end{array}$

Rental Beginning I had trouble understanding the process of acquiring

Application housing. I was not familiar with lease, security deposit and rental agreement. Besides, I did not have any credit history, which was part of the application process, since I had just been here a few days.

Weather Beginning Adjust to the weather of Oregon is very difficult. It gets really cold and it rains a lot here. The first fall I came I started to feel cold and my skin started to itch.

Housing Continuing Finding affordable housing was hard.

Host

Continuing I think the host families charge high rent. Some host

Families families charge $\$ 600$ or more a month. I know a

Charging

High Rent friend who is being charged $\$ 650$ a month by his host family. Other friends of mine paid $\$ 650$ for a one bedroom apartment because they did not know where and how to find affordable apartments. It is all about business. I had two friends who were just feeling really depressed because their host family did not care about them.

Feeling

Out of

Continuing

Place

I felt out of place in class; I felt that I was an outcast. Because I didn't speak the language it didn't mean that I couldn't understand what was going on in class. It was not until after a year or two that the professor knew what I was capable of when I started performing as well as other students in my statistics class.

Adjusting Beginning Adjusting to food was a big challenge for me. Since I to Food did not know my way around, I did not know where to buy food from my country. 
Table 10

Students' Adjustment Challenges (continued)

Theme Group Type $\quad$ Student Responses

Academic Beginning In the first quarter of my graduate program I took a Challenges course without study techniques information and I got a very bad GPA. Consequently, I was placed on academic probation in the first quarter. So in the second quarter I had to read twice as hard as every body else in order to catch up and to come out of academic probation-it was difficult.

Focus Group Question 5: How has the information you received or did not receive impacted you?

Table 11 presents participants perspectives on the impact of the information they received. There were no distinct differences between beginning and continuing international graduate students in terms of the impact of the information they received. The majority of the participants tended to agree that they received none to less satisfactory information on their arrival. Most students said that they depend on a combination of friends, family, and FOCUS (an outside organization) during their transition to graduate school life. There was agreement between beginning and continuing students in terms of one aspect of orientation: both agreed that the most important thing they wanted to know in orientation was housing opportunities. 
Table 11

Impact of Information on Student' Adjustment

Themes Student Group

Making Friends Beginning

Limited Campus

Resources

Information

Lack of On-

going

Orientation

Continuing

Continuing

Interlibrary Continuing

The information I received from FOCUS helped me in many ways. I learned to socialize with other students and to make new friends. FOCUS organizes coffee hour every Friday. Meeting with other international students at the coffee house helped me learn my way around. Even if I wasn't talking, just sitting there, just socializing with other international students and knowing that we were all going through the same adjustment challenges was a fulfilling experience.

I think I did not get the full benefit of the campus recourses because I was not aware of them.

I arrived late so I did not participate in the general orientation. The information I received afterwards from the International Affairs Office was not sufficient. The good thing was that I was transferring from another university and when I had a problem I new where to go to get is solved.

\begin{tabular}{|c|c|c|}
\hline $\begin{array}{l}\text { Accessing } \\
\text { Library } \\
\text { Resources }\end{array}$ & Beginning & $\begin{array}{l}\text { Because did not know my way around the } \\
\text { library, it was hard to access library } \\
\text { resources without help. One time I wanted a } \\
\text { certain article and went to the library, but I } \\
\text { could not find it. The book shelves are so } \\
\text { disorganized that you can hardly find the } \\
\text { resources you are looking for. }\end{array}$ \\
\hline $\begin{array}{l}\text { Interlibrary } \\
\text { Student Loan }\end{array}$ & Continuing & $\begin{array}{l}\text { I never knew that there is something called } \\
\text { Interlibrary student loan. }\end{array}$ \\
\hline
\end{tabular}


Table 11

Impact of Information on Student' Adjustment (continued)

\begin{tabular}{|c|c|c|}
\hline Theme & Student Category & Student Responses \\
\hline $\begin{array}{l}\text { Special } \\
\text { Orientation }\end{array}$ & Continuing & $\begin{array}{l}\text { I was wondering whether there was } \\
\text { special orientation for a particular } \\
\text { course. If this is impossible, are there } \\
\text { good books for this course. }\end{array}$ \\
\hline $\begin{array}{l}\text { Continuing } \\
\text { Students }\end{array}$ & Beginning & $\begin{array}{l}\text { The most helpful orientation I } \\
\text { received was from my senior students } \\
\text { from India. They are the ones who } \\
\text { oriented me. I learned a lot from them. }\end{array}$ \\
\hline $\begin{array}{l}\text { Limited Time for } \\
\text { Orientation }\end{array}$ & Beginning & $\begin{array}{l}\text { The orientation is just for two hours, } \\
\text { which is not enough time to exhaust } \\
\text { all the information helpful in } \\
\text { answering students' questions. I know } \\
\text { the International Affairs Office tries } \\
\text { its best to provide information, but the } \\
\text { information is not helpful at the time } \\
\text { because students are busy trying to } \\
\text { settle down. }\end{array}$ \\
\hline $\begin{array}{l}\text { Need for } \\
\text { Emotional } \\
\text { Support }\end{array}$ & Beginning & $\begin{array}{l}\text { I participated in the orientation and } \\
\text { that was really helpful. During small } \\
\text { group discussions, the student } \\
\text { volunteer, who had been at PSU } \\
\text { before me provided me with helpful } \\
\text { information. }\end{array}$ \\
\hline
\end{tabular}

Question 7: Suppose you were going to give advice to PSU faculty or administration, what specific advice would you give?

Table 12 presents students' responses as to their advice to PSU administration. Students advice included improving academic advising, professors lowering their expectations of international students, involving faculty and staff in general 
orientation, providing departmental orientation, developing a comprehensive graduate program of study, expanding the budget to include the cost of receiving international students, developing work study programs to help students to find jobs, providing cultural sensitivity training to faculty and staffs and developing and implementing an on-going orientation to help students adjust to graduate school.

Table 12

Students' Advice to PSU Administration

$\begin{array}{ccc}\text { Theme } & \text { Student } & \text { Student Responses }\end{array}$

Academic Beginning I think that it is very important that professors and Advising academic advisors be close to students. If I had a good and caring advisor I would not have been put on academic probation because he would have advised me on the courses to take and the best way to study to stay in good graduate standing.

Professors Beginning Professors should lower their expectations of Expectations international students because international students don't communicate as well as the domestic students do.

Financial Beginning I have seen students come from North Korea and Assistance Japan from prosperous families, but not every Programs student that comes here is from a prosperous family. The university should put in place scholarships and grants programs to help students who are in need of financial assistance.

Work Study Continuing International students should be allowed to work more that 20 hours a week so that they can supplement their meager financial resources. 
Table 12

Students' Advice to PSU Administration (continued)

\begin{tabular}{|c|c|c|}
\hline Theme & $\begin{array}{l}\text { Student } \\
\text { Category }\end{array}$ & Student Responses \\
\hline $\begin{array}{l}\text { Improving } \\
\text { Orientation }\end{array}$ & Beginning & $\begin{array}{l}\text { I think the orientation in regard to library } \\
\text { recourses has a little bit of a problem. It would } \\
\text { be nice if the departments helped arrange } \\
\text { international students' tours to the library. }\end{array}$ \\
\hline $\begin{array}{l}\text { Individualized } \\
\text { Assistance }\end{array}$ & Continuing & $\begin{array}{l}\text { I think the professor should make assessment } \\
\text { of international students abilities at the } \\
\text { beginning of the course to find out those who } \\
\text { need individualized assistance, more especially } \\
\text { those whose English is not their first language. }\end{array}$ \\
\hline $\begin{array}{l}\text { Sensitive to } \\
\text { Students' } \\
\text { Need for } \\
\text { Assistance }\end{array}$ & Beginning & $\begin{array}{l}\text { It would be nice for professors to spend a little } \\
\text { more time with students during academic } \\
\text { advising. I felt like every time I went to visit } \\
\text { my advisor, he did things hurriedly just to get } \\
\text { ride of me. }\end{array}$ \\
\hline $\begin{array}{l}\text { Faculty and } \\
\text { Staff } \\
\text { Participation } \\
\text { in General } \\
\text { Orientation }\end{array}$ & Beginning & $\begin{array}{l}\text { One thing that I would have loved to have, had } \\
\text { I been to an orientation, would be to talk to } \\
\text { somebody from my department. It would be } \\
\text { nice if departments sent faculty and staff to the } \\
\text { general orientation so that students can get to } \\
\text { know them. }\end{array}$ \\
\hline $\begin{array}{l}\text { Departmental } \\
\text { Orientation }\end{array}$ & Continuing & $\begin{array}{l}\text { The orientation provided by the International } \\
\text { Affairs Office is helpful, but it would be great } \\
\text { for various departments to conduct their own } \\
\text { orientation for international students. }\end{array}$ \\
\hline $\begin{array}{l}\text { Faculty } \\
\text { Training }\end{array}$ & Continuing & $\begin{array}{l}\text { In the departmental meetings there should be } \\
\text { discussions about how to deal with diversity in } \\
\text { class and how to help foreign students cope } \\
\text { with their new academic environment. }\end{array}$ \\
\hline
\end{tabular}


Table 12

Students' Advice to PSU Administration (continued)

\begin{tabular}{|c|c|c|}
\hline Theme & Group Type & Student Responses \\
\hline $\begin{array}{l}\text { Lack of a } \\
\text { Comprehensive } \\
\text { Program of } \\
\text { Study }\end{array}$ & Beginning & $\begin{array}{l}\text { The graduate handbook is confusing. There } \\
\text { should be a comprehensive graduate } \\
\text { handbook so that students know what to } \\
\text { expect. Sometimes students are not sure } \\
\text { when their comprehensive exams are due. } \\
\text { For instance, there are classes I found out } \\
\text { later that I was supposed to take when I had } \\
\text { thought that I was almost through with my } \\
\text { course requirements. }\end{array}$ \\
\hline
\end{tabular}

Cost of Continuing My advice to PSU administration is that Receiving they should include the cost of receiving Students international students into their budget. The university can offer temporary accommodation for international students if possible and also arrange airport pick up for international students.

Focus Group Question 8: Suppose you were going to give advice to a new

international student who comes from the same background as you, what specific advice would you give this student?

Table 13 illustrates students' perspectives on specific advice they would give to beginning international students. Their advice focused on persistence, finding a host family, talking to senior students, talking to domestic students, meeting with professors and academic advisors very often, and maintaining a good GPA in order to remain in good academic standing. 
Table 13

Participants' Advice to Beginning International Graduate Student

\section{Theme Group Type $\quad$ Student Responses}

Persistence Beginning I would advise the student to learn to be assertive and to learn to find needed information on his or her own.

Host Family Continuing I would say go and find yourself a host family-a good host family.

Students Continuing I think we students should help one another out.

Mentoring If you are going to wait for the professor to help

Students you, it is going to be hard to adjust.

Program

Learning to be Continuing I would advise beginning students to learn how to Independent be independent.

Talking to Beginning I would rather talk to the professor

Professors

Senior Continuing I can't imagine myself without my senior

Students students. They came and picked me up at the airport.

Good Graduate Beginning I would advise a student to maintain a good GPA Standing in order to remain in good graduate standing.

\section{Research Question 5}

What university support resources do students say are helpful?

Students participating in the individual interviews said that academic advising is helpful. Students felt that the issue of academic advising should be addressed at the departmental level so that academic advisers are sensitized about the need to understand how to deal with diversity in class and how to help foreign students 
cope with their new academic environment. Due to their unfamiliarity with the American accent, students have a hard time understanding professors.

Students also felt that career guidance and counseling services are necessary for their overall success. Due to the federal restrictions on international students' employment, international students felt that being allowed to work more than 20 hours a week would help them get enough money to finance their education. While the students understand that the basic reason they are restricted from working is so that they concentrate on their studies, students felt that if a student is able to maintain the required GPA, he or she should be allowed to seek off-campus employment.

While data from the surveys reveals that for the majority of the students, $77 \%$, instruction in the English language was a part of their secondary or college studies, and that their conversation skills were good enough to understand lectures and assignments, interview participants mentioned that they had a hard time effectively participating in class discussion because they feel uncomfortable with the language. The fact that there are some students who still have difficulties with the English language is a challenge for the university.

Students felt that on-going orientation during their entire stay in the graduate school would be a great resource for their success. It is clear from individual interview data that programs dealing with international students' orientation at PSU often have little basis upon which to understand the struggles international students go through. Students felt that orientation should not only be about campus buildings, but also about other campus resources such as banks, off-campus 
housing, book stores, convenient stores, recreational places, and other places of potential interest to students. Students felt that peer mentoring programs are helpful to the newly arrived students and those who need specialized and on-going assistance to cope with and adjust to their new learning environment.

Students said that financial resources to help those international students with pressing financial needs would be helpful. Career guidance and job placement resources were thought to be helpful. Students needed American work experience to be able to help their people back home.

While some students felt that the university was not doing much in way of strengthening the current resources and developing more resources to help international graduate students succeed, a few students thought that international students should also take more responsibility for creating for themselves opportunities and increase their social network.

\section{Research Question 6}

What PSU support resources are needed, but missing?

It is clear from the interview data that on-going international students' orientation is missing. One of the criticisms students had of the International Education Services Office is that the office has failed to develop orientation programs that would help international students with transition to their new learning environment and make connections.

For the purposes of triangulation of evidence, this researcher analyzed documents including project proposals and the Internationalization Action 
Counsel's Strategic Plan. Because a voluntary agency, Friends of Overseas Citizens and University Students (FOCUS), was mentioned several times, the researcher also visited the FOCUS web site to find out the services the organization offers. The researcher also visited the websites of our sister schools in Oregon including the University of Oregon, the University of Portland, Oregon State University, and Lewis and Clark.

Students participating in focus group interviews said that counseling support services were missing at PSU. Students felt that for them to make the most of their stay, good counseling was needed. As noted earlier, first year students need more individualized assistance than do second year international students.

Students felt that international students clubs were missing. These clubs at sister schools help to promote friendship and cooperation among international students. These clubs have proved effective in exposing students to the experiences outside the classroom and beyond the residence hall, helped new international students adapt to the university environment, and provided opportunities for crosscultural exchanges in the university community. As students meet and share their ideas and experiences, international understanding becomes a reality.

International student mentoring support services are missing. Data from the University of Portland's website suggest that student peer mentoring programs are important for international students' adjustment. One of the mentoring programs that exist at the University of Portland is the International Peer Health Educators program (IPHEs). Each year two international students serve as International Peer Health Educators. These students are available to talk with international students 
about academic, personal, or health related issues. They also develop programs to help international students maintain health and balance during their adjustment process to life in the United States.

Another mentoring program at the University of Portland and the University of Oregon that seems to be missing at PSU is the International Short-Term Mentor Program. The International Short-Term Mentor program matches new international students with returning international students for advice and support related to social, academic, and cultural adjustment. The short-term mentor program lasts two to four weeks.

Career guidance and counseling services for international students are missing. Our sister schools such as the University of Portland and the University of Oregon have introduced the International Job Club with the goal of supporting international students by finding them jobs and advising international students on the issues of job search. The program works in collaboration with the Office of Career Services. Workshops are offered to international students to meet their specific needs in the U.S. job market. Topics such as resume building, interviewing, and networking are examples of the skills developed during the workshops. Such programs are missing at PSU.

Financial support resources for international graduate students were reported by the participants as missing at PSU. There was a general consensus between beginning and continuing international graduate students that facilities for financial assistance to foreign students are limited. They also acknowledged that limited scholarships and fellowships are available to international students. Financial 
challenges include unexpected high cost of rent, food, cleaning and laundry, clothing, books, medical care, and incidentals.

An information clearing house is missing. Students said that they needed a lot of new information in order to settle down. Some students mentioned that they felt overwhelmed and frustrated with all they have to do before starting school. Lack of knowledge of campus facilities and available resources, restrictive immigration regulations, loneliness, homesickness, and lack of organized cultural and social opportunities were some of the impediments to students' adjustment.

There were contrasting views regarding the issue of host family support services. Some students appreciated the help host families extended to them in regard to educating them about the American system, but some students were skeptical about the motives of host families and felt that host families were business oriented and that they charged high rent. Some students felt that host families were just interested in collecting money from students rather than helping students with their adjustment needs. Some students didn't see any difference between host families and other housing management companies.

It was found that while continuing students go through the same challenges beginning international graduate students go through, continuing international graduate students have learned the ropes and are able to access required information with little or no difficulty. Beginning students need more details on issues ranging from how to study for class, to which study techniques are necessary to keep a graduate school required B average, to finding affordable housing. 


\section{Results of Surveys}

After the focus group interviews and in-depth interviews, a survey questionnaire was developed. To establish survey validity, the questionnaire instrument was reviewed by my academic adviser then pilot tested on sixteen participants (three individual interview participants, and thirteen focus group participants) who had experienced graduate school adjustment challenges. Input received from the pilot test group and the experts was incorporated into the survey instrument.

The 24-item survey questionnaire contained three sections: personal, school, and general information. The personal section asked about student gender, age, marital status, and home region. The school section asked about, student major, vocation objective, year of arrival at PSU, year of degree completion, and expected year of return to home country. The general information section asked about how students learned about PSU, whether or not they received sufficient information, the official agency receiving them on arrival, whether English was part of their secondary or college studies, how and where they acquired conversation skills, whether or not their housing conditions were sufficient for their needs, whether or not they are satisfied with their financial aid and time for study, how well they were received by PSU and by the communities where they live, and whether or not they participate in religious activities of any kind.

Surveys were sent to all international graduate students through the International Affairs Office, but targeting 60 international graduate students. Fortyfour surveys were returned by the requested date. As the survey data indicates, the 
survey responses are weighted quite heavily toward continuing students- $21 \%$ $(\mathrm{N}=9)$ were beginning and $79 \%(\mathrm{~N}=34)$ were continuing international graduate students. Of the 43 students, $60 \%(\mathrm{~N}=26)$ were males and $40 \%(\mathrm{~N}=17)$ were female (Figure 1).

Figure 1. Gender

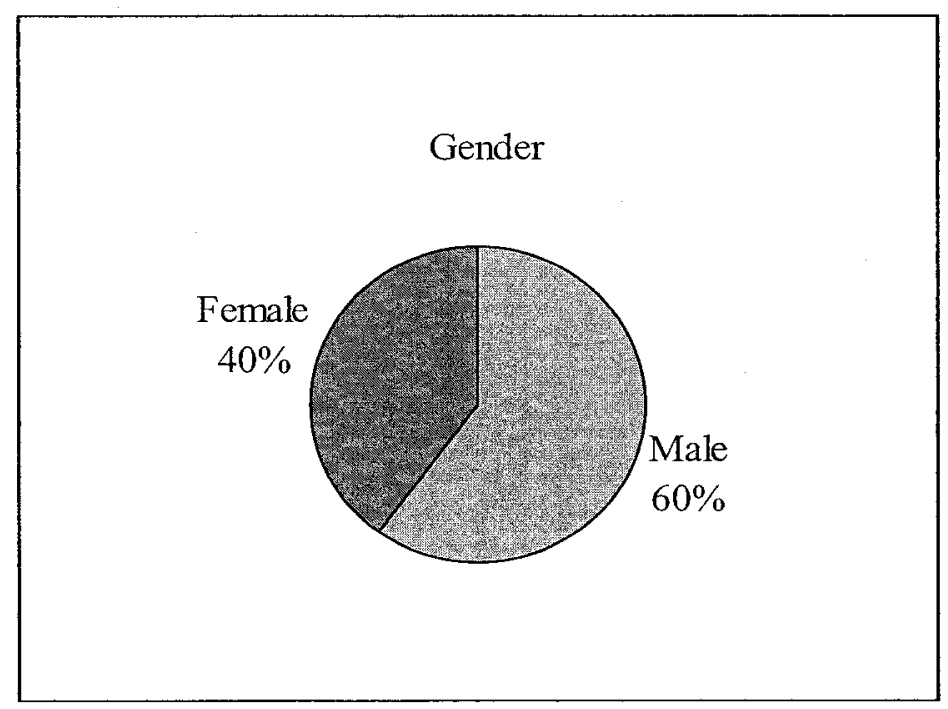

On the question of age, $39 \%(\mathrm{~N}=17)$ were between the ages of 27 and $30,21 \%$ $(\mathrm{N}=9)$ were between ages 31 and $34,19 \%(\mathrm{~N}=8)$ were between ages 35 and $38,5 \%$ $(\mathrm{N}=2)$ were 40 and over years of age (see Figure 2). 
Figure 2. Age.

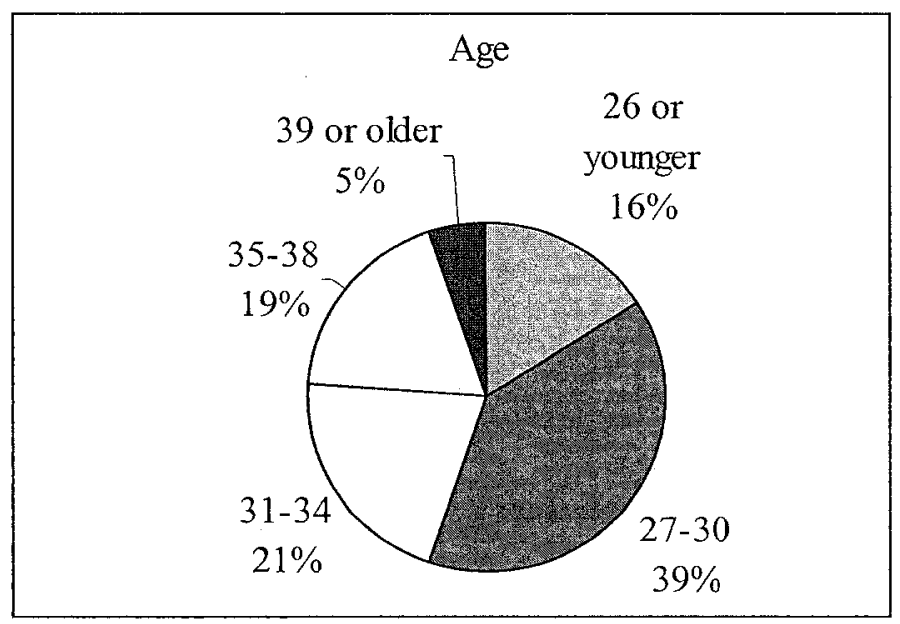

The majority, 37\% $(\mathrm{N}=16)$ were from Asia, Africa 19\% $(\mathrm{N}=8)$, Europe $16 \%$ $(\mathrm{N}=7)$ Middle East 19\% $(\mathrm{N}=8)$ and Latin America 9\% $(\mathrm{N}=4)$ (see Figure 3$)$.

Figure 3. Regions of Origin.

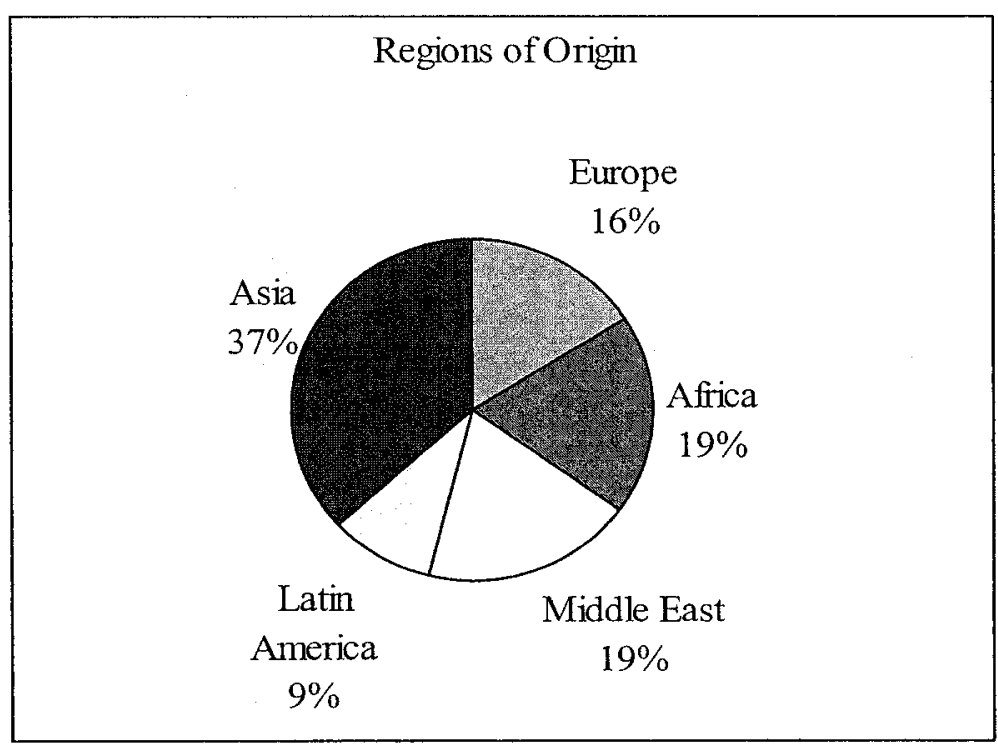


On the year of arrival, $28 \%(\mathrm{~N}=12)$ arrived in $2003,23 \%(\mathrm{~N}=10)$ in $2004,21 \%$ $(\mathrm{N}=9)$ in $2005,9 \%(\mathrm{~N}=4)$ in $2000,9 \%(\mathrm{~N}=4)$ in 2001 , and $9 \%(\mathrm{~N}=4)$ in 2002. Survey responses are weighted quite heavily toward continuing students; 9 are beginning and 34 are continuing students.

The majority of the students, $81 \%(\mathrm{~N}=35)$ were single and $19 \%(\mathrm{~N}=8)$ were married (see Figure 4).

Figure 4. Marital Status

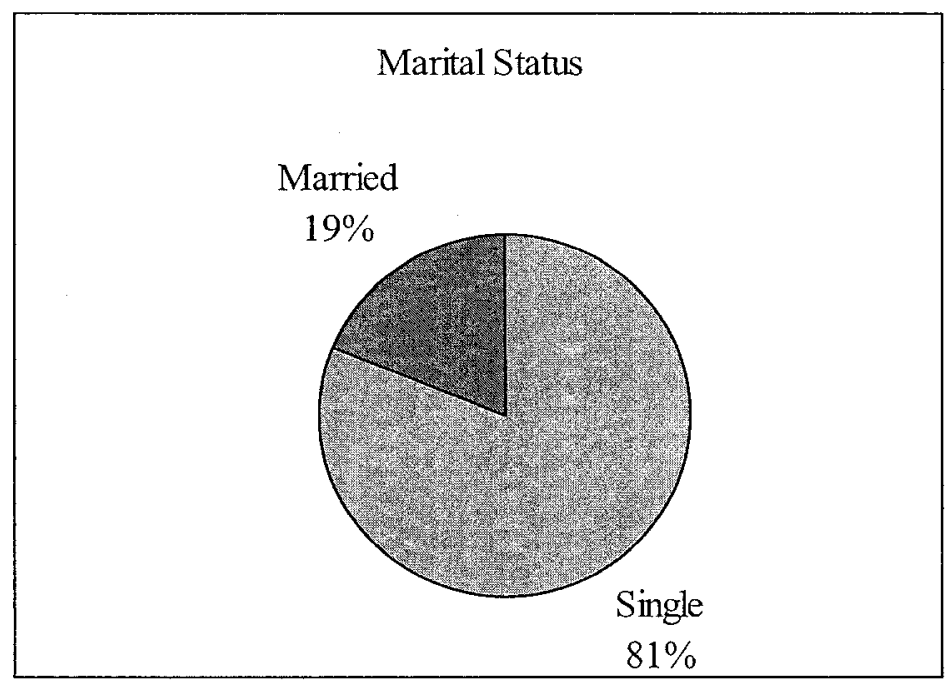

On academic unit, $56 \%(\mathrm{~N}=24)$ were from the College of Liberal Arts and Sciences, $30 \%(\mathrm{~N}=13)$ School of Engineering and Computer Science, $12 \%(\mathrm{~N}=5)$ School of Education and $2 \%(\mathrm{~N}=1)$ other (see figure 5$)$.

The majority, fifty-two percent have studied English for two to five years, twenty-nine percent, six to nine years, seventeen percent, one year or less, and two percent studied English for ten or more years (see Figure 6). 
Figure 5. Academic Unit.

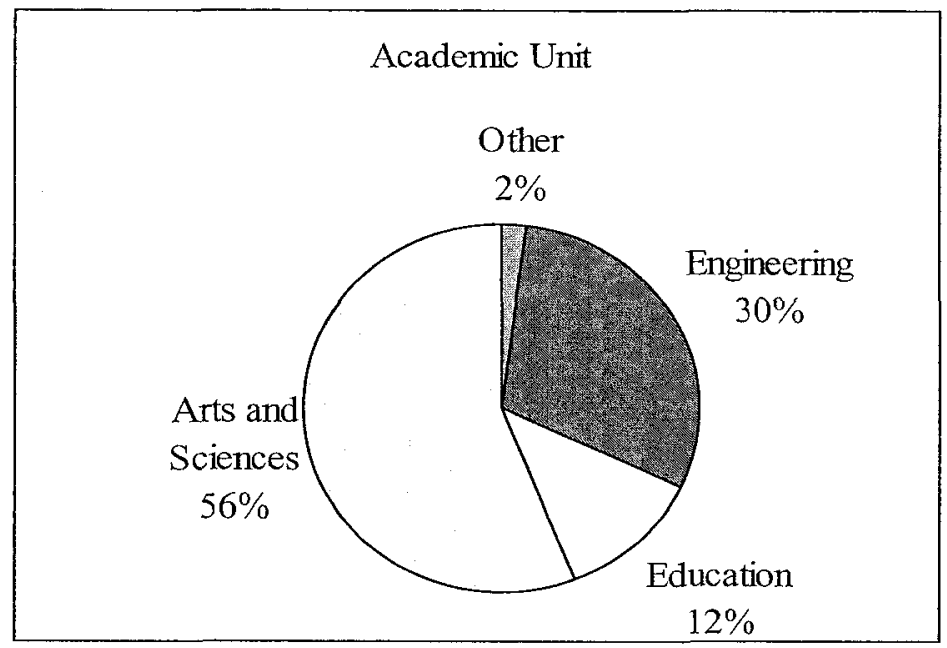

Figure 6. Years of English

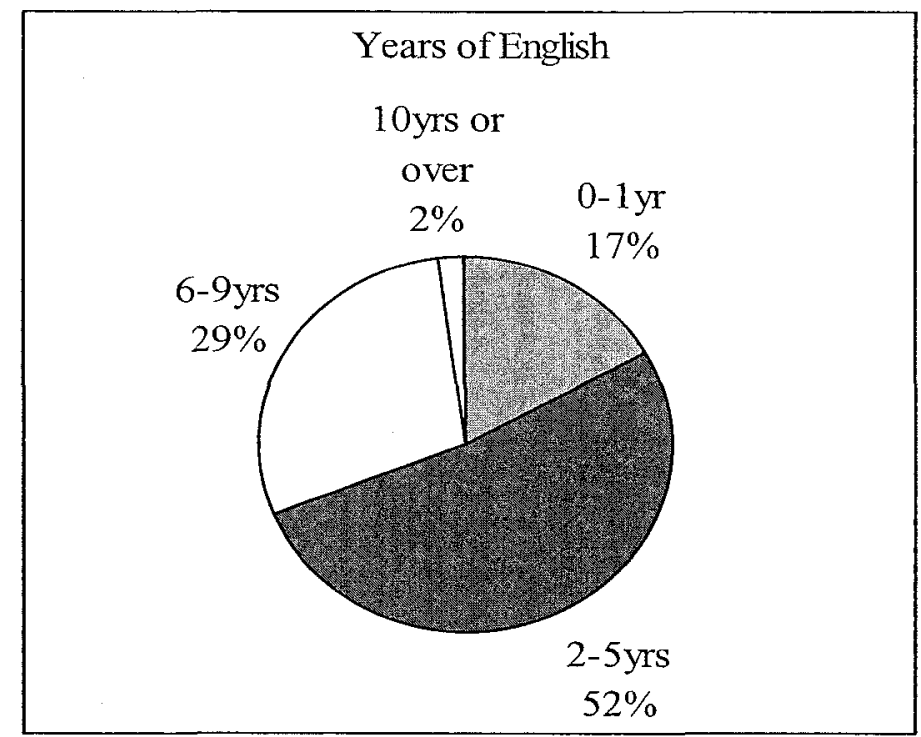

The GPA of the students indicated that all the students were in good academic standing. Forty percent reported GPA between 3.00-3.20, seven percent 3.21-3.40, twenty-three percent 3.41-3.60, thirty percent 3.61-3.80, and none with GPA of 3.81 and over (see Figure 7). 
Figure 7. GPA.

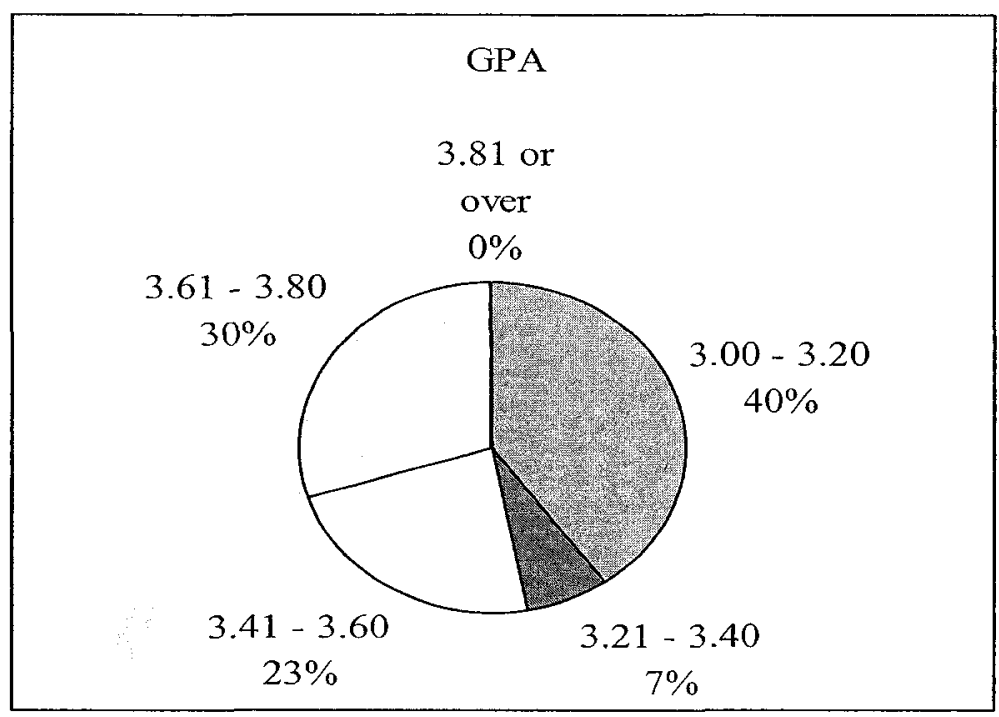

Students were asked to respond to 13 general questions. On the question of where they learned about PSU, the majority, $72 \%(\mathrm{~N}=31)$ said that they learned about PSU from sources other than PSU. The majority, 93\% (N=40) of the students strongly disagreed or disagreed that the information they received during orientation was sufficient for their needs. On the question of whether there was an official agency that aided them on their arrival at PSU, 81\% $(\mathrm{N}=35)$ strongly disagreed or disagreed that there was an official agency that aided them on their arrival in Portland.

On the question of whether English language was a part of their secondary or college studies, $77 \%(\mathrm{~N}=33)$ agreed; $70 \%(\mathrm{~N}=31)$ acquired their conversation skills through school. Fifty-eight percent $(\mathrm{N}=25)$ said that their conversation skills were good enough to understand lectures and assignments, $77 \%(\mathrm{~N}=33)$ said that they were dissatisfied with their housing facilities, $88 \%(\mathrm{~N}=38)$ said that their health condition was good, $91 \%(\mathrm{~N}=39)$ feel that the financial aid they are receiving is 
insufficient for their needs, $67 \%(\mathrm{~N}=29)$ do not have other sources of financial aid in addition to scholarship, and 33\% (N=14) have additional sources of financial aid.

On the question of whether students had sufficient time to do their home work, $86.1 \%(\mathrm{~N}=37)$ said that they have sufficient time to do their assignments, $72 \%$ $(N=31)$ said that in general, they had been received on equal terms by American classmates, $54 \%(\mathrm{~N}=23)$ said that in general they have been well received by people on campus, and $47 \%(\mathrm{~N}=20)$ felt that they had not been received on equal terms by people on campus.

On the question of whether students participate in religious and other nonacademic activities, $56 \%(\mathrm{~N}=25)$ strongly disagreed or disagreed, and $44 \%(\mathrm{~N}=19)$ strongly agreed or agreed that they participate in religious or non-academic activities.

Note. Scale: $1=$ Strongly Agree, $2=$ Agree, $3=$ Somewhat agree, $4=$ Disagree, $5=$ Strongly Disagree.

The majority, $77 \%(\mathrm{~N}=33)$, of the respondents said that they were dissatisfied with their housing facilities, $88.3 \%(\mathrm{~N}=38) 91 \%(\mathrm{~N}=39)$ feel that the financial aid they are receiving is insufficient for their needs, and $67 \%(\mathrm{~N}=29)$ do not have other sources of financial aid in addition to scholarship.

\section{Major Themes}

Initially, I identified many themes which were collapsed into eight major themes found during the data analysis. These themes include (a) gap between students' expectations and reality, (b) issues and concerns, (c) misattribution, (d) 
academic challenges, (e) social/cultural challenges, (f) health/psychological challenges, $(\mathrm{g})$ financial challenges, and $(\mathrm{h})$ housing challenges.

Gap between Students' Expectations and Reality

It is clear from the students' focus group and individual interview responses that there is a widening gap between graduate school requirements and international graduate student expectations. This gap is connected to international students not clearly understanding what it is really takes to go to school--unrealistic expectations. International students rely on the International Affairs Office to provide a bridge between the PSU academic programs and international student population. Unfortunately, the office is not the first source of students' information—students rely on fellow students and outside organizations for orientation and needed help for adjustment. Some students said that they experienced financial and other adjustment challenges because of the limited information they received prior and on their arrival at PSU. One student said that lack of appropriate financial information made him plan inappropriately for his stay, consequently he run out of his savings and encountered financial difficulties.

It is critical that programs dealing with international students understand both international students' expectations and graduate school demands in order to effectively facilitate international students' adjustment to graduate school. Other students identified problems with the language and meeting professors' expectations. While the professors expect international students to present satisfactory work, speak English correctly, and write appropriately, focus group 
responses suggested that international graduate students come from different academic backgrounds and that most of them have a problem with the English language. The inability of the international students to speak and write well, the failure of the university and faculty to detect the students' language difficulties frustrates students.

Based on focus group data, students' opinions of the university are greatly shaped by the treatment they receive on their arrival at PSU. These international students expect attention from international student counselors, professors, and from the entire campus community, and when students do not receive the attention they expect, students get frustrated, hence developing negative opinions of the university and purposely avoiding seeking help from departments designed to help them.

The results of focus group and individual interviews strongly reinforce the central place of on-going orientation for international graduate students. It is clear from the students' perspectives that the International Affairs Office is most interested in enforcing the immigration rules and regulations, and think that some aspects of rules enforcement pose adjustment challenges to international graduate students. One student argued that instead of being restricted to twenty hours a week of work, international students should be allowed to work more than 20 hours a week so that they can get money for their education.

It is clear that international students pay out of state tuition and expect special attention and extra academic and social services, but the university has not been able to do that well. While the university has relied heavily on FOCUS to provide 
orientation programs, many students see the university's over reliance on the FOCUS organization as a diminished role for the university, with the FOCUS organization marketing itself directly to international students, most of whom do not agree with its religious views. One student from Asia said that he refused to be helped by the FOCUS organization because he was not sure about its relationship with PSU. Another student suggested the adoption of the FOCUS programs by PSU so that students don't have to run from place to place looking for help.

The gap between the graduate school demands and the personalization expectations of students suggests that on-going orientation promise greater efficiency in students' adjustment. It is also important that the Internationalization Action Council and the Diversity Action Council provide an avenue for a dialogue on several issues raised in this study, particularly as they relate to attracting, recruiting, and retaining international graduate students. One way to facilitate this dialogue could be to initiate collaboration between the aforementioned councils by bringing together students, foreign exchange professionals, international student counselors, faculty, and university administration to talk about the best way to make international graduate students' graduate school life a worthwhile experience.

\section{Issues and Concerns}

This study serves to shed light on both the challenges and opportunities that come from working with and helping this population adjust to its learning environment. Specifically, the goals of the focus groups were to determine the challenges these students encountered in adjusting to graduate school, the support 
they need and want in order to succeed in their degree programs, to better provide the students with necessary support services.

On the issue of the difficulties faced by international graduate students, the focus group participants were overwhelmingly in agreement about their adjustment challenges. Those most often mentioned were related to housing, especially due to students not being familiar with the process of renting (security deposit, lease and rental agreement, credit history) and the high cost of rent. Students mentioned additional challenges including lack of English proficiency, economic hardships, lack of knowledge of campus facilities and available resources, restrictive immigration regulations, loneliness, homesickness, and lack of organized cultural and social opportunities.

On the issue of the adjustments needed to make in their first year in graduate school. Beginning international graduate students mentioned that they needed assistance with travel expenses, finding appropriate accommodation, finding classes on their first day, making sense of the American university system, and learning how to interact with faculty, administration and fellow students.

On the issue of the challenges faced by continuing international students, students said that they arrived in Portland with lots of needs to satisfy. Continuing international graduate students are especially more mature than undergraduate international students. Most of them have worked in their native countries before, and a big majority support themselves financially. They feel lonely and need support in numerous domains, and the International Education Services Office can only fulfill a certain number of their needs. They need a lot of new information in 
finding jobs to support themselves financially, more information on completing their course requirements and completing their comprehensive exams and theses/dissertation.

Regarding ways in which the perspectives of continuing international graduate students are similar to perspectives of first year international graduate students, there was a unanimous agreement among beginning and continuing graduate students that they needed information on settling down in Portland (e.g., housing, bank, phone, and stores); getting started with school (registration, tuition, fees, and scholarships); Immigration and work (Visa, Travel issues, Work Permit and practical training); how to file for taxes returns; getting to know people (academic advisors, student support staff, counselors, and other international students).

On the issue of support resources, students indicated a need for programs to orient students to the American education system, and mentoring programs. They stated that cultural programs leaves them with little preparation to guide them to make appropriate choices of classes, majors and plan for completion of their degree programs. At the same time, academic advisors are not aware of the traditional cultures of international students. Instructors have trouble engaging international students who may be struggling with English and the American higher education system. International students often have as much or more difficulty participating in campus activities or completing their assignment. Students also felt that they need assistance in understanding the U.S. higher education system, and exposure to peer mentoring and counseling in addition to assistance in accessing the mainstream student services available through campus resources. 
Focus group participants expressed a need for on-going orientation, academic and cultural programs that are intentional, flexible, and geared toward students needs for adjustment to graduate school. They also need information on specific courses, information related to special needs, either in general or about the specific need with which they were dealing (e.g., information on what are realistic expectations for international students with limited English proficiency, information on adaptive communication, ideas for activities). Using simple language that is easy for international students to understand and to avoid colloquial language that is understood only by native speakers of English would be helpful. A very popular resource request among the focus group participants was to allow them to work more than the federal requirement of 20 hours a week.

It is clear from the focus group data that first year students tended to need usable guidance at appropriate time, especially on how to get from the airport to campus, finding appropriate accommodation, finding classes on their first day, making sense of the American university system, and learning how to interact with faculty, administration and fellow students. It was found that, although continuing students go through the same challenges first year international students go through, continuing international graduate students have learned the ropes and are able to access required information with little or no difficulty. First year students need more details on issues ranging from how to study for class, to which study techniques are necessary to keep a graduate school required B average, to finding affordable housing. 
Misattribution

The issue of misattribution can be seen from the standpoint of both professors and international students. In one incident one international graduate student narrated her encounter with an international professor. The student sent an e-mail to the professor with a request, but the professor expected the student to ask for a favor. The student interpreted the professor's motives as biased and culturally insensitive. At the same time, the professor interpreted the students e-mail as rude and inappropriate. In another related incident, one student complained about the professor giving him a low grade. In this incident, the student did not follow instructions, and yet the professor has to be biased and prejudiced. Another student complained that the professor did not give her special attention when giving assignment. Another student complained about the professor unrealistic expectations. It is clear that professors may try to be strict with international students for fear of being taken advantage of; however, lack of understanding of international graduate students' adjustment challenges can creates a sense of estrangement between professors and students. It is imperative, therefore, that professors exercise caution when dealing with international students and make sure that students get the help they need to succeed in class.

Several issues combine to result in an unfortunate experience for students - not following instructions, not being able to talk to a person in authority. One issue that seemed to be important to participants in both focus groups had to do with how differences in cultural background affected the likelihood of seeking help. Both beginning and continuing students recognized that differences in cultural and 
educational backgrounds existed, and they would do better in class if a professor who taught to their particularly level of understanding.

\section{Academic Challenges}

It is clear from the focus group data that when international students first start taking academic classes, they experience several concerns related to understanding classroom instruction, participating in classroom discussions, or figuring out the professor's expectations. Students also tend to worry about achieving their academic goals in order to graduate. Those who have been here more than one academic year were more likely to experience less academic challenges compared to those who had been in America for less than one academic year.

The complaint of lack of framework and direction in the graduate academic program was found most frequently in both the individual and group interviews. This fits the common perception of the unavailability of orientation programs that are intentional and flexible to provide help needed in connection with personal and academic difficulties. The unavailability of academic counseling and mentoring programs for international graduate students at PSU may explain this finding.

The problem of proper orientation on arrival is most serious in first year graduate students. The issue that most international graduate students deserve more attention is not an issue taken seriously by university. Somewhat less serious, apparently, is the feeling among international students that the International Affairs Office is not doing much to provide social support on their arrival. This is probably because the office [by default, not intention] has left the responsibility of 
socializing students on their arrival in Portland entirely to FOCUS (Friends of Overseas Citizens and University Students), a religious organization that is not sponsored by PSU. Difficulties in dealing with professors are much more frequent. This is compounded by the students' difficulty in understanding the American education system.

\section{Social/Cultural Challenges}

The initial challenges of the students tend to be related to finding a place to live, learning where and how to shop for groceries, finding transportation or figuring out how to use a public transportation system, registering for classes, and setting up a communication medium (i.e., phone, e-mail) to reach loved ones back home. Airport pick-up services organized by the International Affairs Office, a host family for the initial stay, and matching the student with another international student before his/her entry to the U.S., might be ways to ensure that students will have a more successful transition.

International graduate students at Portland State University feel isolated within the larger student body. Little interaction occurs between these students and the other cultural groups. It is understandable that cultural differences, which may affect academic success, occur amongst students at most universities, and Portland State University is no exception.

It is clear from the in-depth interview data that international students may display various reactions to the host country and culture. The similarity between the students' home culture and the host culture, perceived discrimination, being 
extraverted, having high communication skills in English, and a positive approach to forming relationships with Americans all facilitate a successful transition. Data from the focus groups suggest that students from some other cultures (i.e., Asian and African cultures) may feel distant to the American culture and experience more adjustment difficulties. Furthermore, as the level of perceived prejudice increases, so does the likelihood that international students will identify with other international students rather than host nationals (Constantine, 2003).

The majority of focus group participants mentioned that they did not receive information regarding finances and accommodation, and the difficulty of obtaining the necessary information was often mentioned. Among those who received an orientation, the information was not helpful in answering their immediate questions. In this present study, I was surprised to find that in addition to not receiving adequate information before arrival, those who did get information, received from sources other than PSU. This may have been due to their lack of initiative, but it is highly probable that in many cases they simply found it difficult to discover where, and from whom, such information could be obtained.

Finding appropriate information seems to be a matter of high priority deserving the attention of administrators supporting the international education program at PSU. The importance of adequate preparation in the use of English language deserves more emphasis, and my experience during the course of this study indicates how important it is to be aware of how essential such skills are to successful adjustment. 
There was a noticeable difference between the survey data and interview data on students' level of English proficiency. In the survey data the majority of the students indicated that they had six or more years of English language instruction and that they understand English well enough to understand lectures and assignments. However, data from the individual or group interviews suggested that students experienced limited English proficiency. In fact, many of the international students participating in the interviews spoke of the importance of the language factor, and indicated that they were inadequately prepared in the language and that they have to spend much a large part of their time learning to listen, read, and write with reasonable proficiency.

Health/Psychological Challenges

Although the majority of the students participating in the survey said that their health was good, it is clear from focus group data that during their initial transition, international students feel lost, confused, overwhelmed, helpless, and isolated. As they try to settle in to their new environment with the start of the quarter, they may also feel academic stress similar to their domestic counterparts. However, unlike the other students, international students usually do not have similar resources to combat this stress. This lack of resources coupled with a different adjustment experience lead to homesickness, depression, or anxiety. 
Financial Challenges

Difficulties with finances are reported with great frequency. It was evident in the students' responses that financial adjustment challenges create serious problems in the adjustment of a substantial proportion of international graduate students. Many of them come to PSU with fellowships and, in their case (as our interviews indicate), the major complaint is that the monthly or quarterly stipends are insufficient for students' needs. One interesting finding, however, was that students from Africa were more likely to experience financial difficulties than students from Asia. Students from Asia are mostly supported by their families and government, while most of the students from Africa supported themselves, additionally many are frustrated by federal regulations forbidding remunerative employment, and their inability to work further exacerbates their financial adjustment challenges.

\section{Housing Challenges}

Survey data revealed that the majority $77 \%(\mathrm{~N}=33)$, who participated in the survey were dissatisfied with their housing facilities. There was a general feeling among the majority of the students who participated in the survey that there were not enough accommodation available at prices within the range of foreign students' income. The difficulties which arise as a consequence represent one of the major sources of complaints by students. As for the kind of accommodation, no clear consensus emerged regarding what constitutes appropriate accommodation. The most reasonable conclusion is that some students are happier in dormitories, others like to live with host families, others like the idea of living with students from their 
country, and still others prefer to live by themselves. It appears to be impossible to offer a specific suggestion, other than to say that affordable housing is not sufficiently available to students at PSU. The lack of affordable housing was found to be one of the greatest of obstacles to students' adjustment.

It is important to note that among students there is often a more or less philosophical acceptance of certain adjustment challenges as being inevitable, and an accompanying refusal to allow them to spoil the total adjustment experience. Nevertheless, the challenges encountered by students are not unimportant, nor should they be ignored by those responsible for international students. Obviously, the sooner these obstacles to successful transition can be addressed, the better for the international students' graduate school experience and the better for PSU as a community supporting higher education. 


\section{CHAPTER V}

\section{PERSONAL REFLECTIONS}

This chapter discusses the challenges I encountered in adjusting to graduate study both at the University of Portland and at Portland State University. The challenges included academic, health, housing, social, and cultural adjustment issues. In 1998, I received a scholarship from the Holy Cross congregation of East Africa for a Master of Arts degree at the University of Portland. The scholarship covered tuition, books, room, and board. Even though the scholarship was awarded with the understanding that I would go back to Uganda upon graduation, to work with the Catholic Church, I visualized the need for broader school reform in Uganda. During the last semester of my master's program at the University of Portland, I decided that I wanted to complete a doctorate. I strongly believed that completing a doctorate would equip me with the administrative skills needed to guide Uganda's school improvement efforts.

Although I fulfilled the academic requirements for admission to a doctoral program, one big challenge remained: to secure funding and proof of financial support - always a requirement for international students' admission. I contacted the Holy Cross congregation in Portland and requested financial support, but my request was denied. Owing to the fact that I could not secure funding, I started making arrangements to return to Uganda. 
One day I met a man on the bus and, from my conversation with him, I learned he was a retired medical doctor. Over time, we became good friends and communicated regularly through telephone and e-mail. This man eventually became my sponsor.

Towards the end of my first year my sponsor withdrew his financial support. This considerably exacerbated my financial situation. The unexpected high costs of rent and utilities, food, cleaning and laundry, clothing, books, medical care, and incidentals further compounded my financial problems. Early in my doctoral program, I searched for fellowships and scholarships, academic stipends and assistantships, and all kinds of employment opportunities and loans that would carry me from quarter to quarter. I did receive work study and Graduate Assistantship support, but the support was not enough to cover my fees, housing, books, and food. My financial difficulties were compounded by employment restrictions faced by international students.

In the winter of 2001, I went through a rigorous and cumbersome application process to secure a curricular practical training authorization through the International Affairs Office. Curricular Practical Training (CPT) is an employment option available to F-1 students where the practical training employment is considered to be an integral part of the curriculum or academic program. According to the immigration regulations, this employment may be an internship, cooperative education job, a practicum, or any other work experience that is either required for an international student's degree or for which academic credit is awarded. To be eligible for curricular practical training, I had to have been enrolled on a full-time 
basis for one full academic year, my employment needed to be an integral part of my degree program or requirement for a course, and my job offer related to my major or field of study. I also needed to have an offer of employment offering work that qualified as curricular practical training.

In the fall of 2001 I received a job offer from the Catholic Charities that suited the requirement for the curricular practical training. I worked as a Caseworker for the African refugee program. From the monthly income of $\$ 800$, I was able to make a $\$ 200$ monthly payment toward my school debt (which by this time was over $\$ 3,000$ ). Because the job required me to drive, I financed a car and had to pay a monthly car payment. After one year, my job ended and my financial situation worsened. At that time the Accounts Receivable Director at PSU and I reached an understanding that I would pay $\$ 50$ per month to cover part of the debt I owed PSU. Although I was consistent with my $\$ 50$ monthly payment, that arrangement proved to be fruitless, to the extent that $\$ 100$ at the end of every quarter was assessed to my student account as a penalty for late payment--the biggest percentage of the debt I owed PSU was an accumulation of the $\$ 100$ penalties for late payment and accrued interest on those penalties. I was also unable to pay my monthly car payments and my car was repossessed. This jeopardized my credit record, making it extremely difficult for me to buy anything on credit. My recurring school debt and quarterly struggles to gain special permission from accounts receivable to register, causing me much stress. At one time I contemplated dropping out of my doctoral program. 
Another challenge concerned academic adjustment. Despite the fact that I spoke and understood English very well, it was hard to adjust to the American accent and to follow lectures. Whenever classes convened, I became anxious because I could not complete the assignments on time. Unlike the Ugandan education system, where the syllabus, grading, and scoring of exams are centralized, the American higher education system gives professors complete autonomy in regard to designing the syllabus, grading, and scoring exams and quizzes. I also noticed that the grading system is based on many subcategories including, but not limited to, class participation, midterm quizzes, homework, final exam, and peer evaluation. In some classes, if students do not evaluate their peers the students may lose some points, which affects their final grades. I found it difficult to adjust to this educational system.

One of the most onerous academic challenges with which I had to contend happened in one research class. I noticed that the professor was prejudiced. Whenever I asked a question the professor either answered me rudely or he deliberately refused to acknowledge my question. The professor's attitude toward me interfered with my ability to understand and internalize his lectures. I felt that the professor was intentionally deriding my ability to participate in class. Virtually all of his comments about me were derogatory.

One day I developed a health problem, and I went to this professor and asked for permission to go to the Student Health Services to see a doctor. The professor said to me: 
This department is not the Graduate School of Education. I know it is extremely difficult for students from the Graduate School of Education to come here and catch up to speed with students in this department. I'm even wondering whether you are following or whether you understand what is going on in this class. If you are having a hard time understanding me, I would be more than happy to make referrals for you to some special education services on campus.

The professor's deprecating comments about me made me despondent. In one of our class meetings, the professor had invited a renowned researcher to talk about focus group research. During class discussion I asked a question about whether focus group research is a research method or a data collecting strategy. The professor became very upset and said that I was impugning his knowledge of focus group research. The professor asked me, "Are you trying to tell me how to teach this class?" At that time, I had the temerity to tell this professor that his arrogance was affecting my ability to learn. This seemed to make him more angry. During the class break, I overheard the visiting professor say to this professor: "That guy had interesting and legitimate questions."

I should like to mention that this professor does not represent the views of other professors at PSU. I have met many professors at PSU who are approachable, helpful, and kind to international students. It is worth noting, though, that such a professor can create among international students a sense of estrangement and a feeling of resentment toward other professors.

In addition to various financial, educational, and academic adjustment challenges, I also encountered a health adjustment challenge. During my first year at PSU, I developed a fever and went to a private clinic in downtown Portland to seek treatment. The clinic charged me a lot for a doctor visitation because I did not 
have health insurance. The reason I went to a private clinic was that I was extremely cautious and I always took great care to not share my health problems with the International Education Services personnel or with my academic adviser. I was concerned that if they found out anything was wrong with my health, it might jeopardize my immigration status. This fear pared my ability to seek helpful information. Moreover, I was not aware that the Student Health Services existed at PSU and that my Assistantship covered my health insurance at that time. This was because I started my program in the summer and I did not receive any orientation. In June 2005, I got involved in an automobile accident. The other driver made an improper lane change and hit me. After the accident, I was rushed to the hospital. A medical procedure was performed, fortunately, there were no broken bones found. As a result of the accident I went through an excruciating level of body pain for a long time. This pain affected my ability to concentrate on my school work. Although I regularly visited the Chiropractic Physician for physical therapy and massage therapy, I continued to experience a great deal of lower-back pain, and my inability to recover from it exasperated me exceedingly.

Two weeks after the accident, I developed a fever with a temperature of 100.4 degrees and again went into the Emergency Room. Another medical procedure was performed and I was diagnosed with a health problem related to the car accident, which needed treatment. The doctor put me on a two-week antibiotics treatment and said that if the infection was not serious, the antibiotics might help prevent it from developing into something serious. 
After two weeks of my antibiotic treatment, I went back to see the doctor. The doctor again performed another medical exam and the results came back normal. However, the doctor ordered yet another medical procedure to be performed on me. The procedure was performed and the results came back normal. The doctor prescribed a series of doctor visitations. I was lucky that the insurance company of the driver who hit me paid my medical bills. I was also able to contact a lawyer, who helped me to file an injury claim. I'm hopeful that when my claim is settled, I will be able to pay off the money I owe Portland State University.

Another adjustment challenge I encountered concerned housing. Realizing that I could not afford to live in campus housing because of the high cost, I rented an apartment in downtown Portland. But soon I realized that the standard of living in downtown Portland was very high. I was forced to break my lease and forfeit my security deposit in order to move to an apartment outside of Portland where rent was more affordable. Moving into a new neighborhood did not solve my housing problems, however. One day my car was broken into and my school bag, personal checks, and text books were stolen. One day I went to my bank to check my account balance and I learned from the banker that I was a victim of identity theft. I spent almost one whole quarter at school cooperating with police on the case. Even though the culprit was eventually apprehended, the situation caused me much stress and I lived in constant fear thereafter. Eventually, I had to move to yet another location. I always felt that had I been given a formal orientation, addressing matters like housing, I never would have gone through the aforementioned challenges. 
I also encountered numerous challenges during my work-study and graduate assistantship duties. In one of the offices where I worked, I noticed that the majority of the students with whom I worked were from Asia. Although most of them were undergraduates and younger than I was, I always felt I was a minority among the minority group. My discomfort was compounded by the fact that the manager was also an Asian student who, I think, was prejudiced toward me. Because he spoke the language of the majority of the Asian work study students, he always came to the front desk to chat with them in their language. I noticed that he was treating me differently from the Asian students-he was unfriendly, rude, and arrogant to me. Every time I greeted him he refused to respond. Every time I asked him a technical question, he ignored me and walked away. One day, the work-study students, who worked in that computer laboratory, had a meeting with the director at the opening of a new quarter. While waiting for the director, I sat at one of the computers to check my e-mail. This manager walked toward me and yelled at me that I had messed-up his computer program. I became indignant when he accused me of messing-up his computer program. The computer was completely shut down when I logged on, and I could not possibly have impacted his computer program.

Because most of my Graduate Assistantship obligations could be accomplished in my home, I requested that the office manager lend me a computer so that I could work from home. The director accepted this and told me to talk to the Manager to obtain the computer. When I talked to the office manager about the computer, he refused to give it me. The director then insisted that the office manager give me the computer, which he finally did. When I took the computer home, I realized that it 
had a technical problem. I reported the problem to the laboratory director. The director asked me to bring it back to the manager for repair. When I brought back the computer to the office manager, he repaired it and gave it away to someone else. I wrote to the director and requested an audience with him and the manager. In the meeting I expressed my concern about the way the manager was treating me. Although the director tried the best he could to resolve the conflict, the manager did not change his attitude. To resolve this conflict, I decided to use other resources on campus where I could do my graduate assistantship work without such intimidation and harassment.

The preceding story illuminates several personal adjustment challenges including academic, health, housing, relational, and cultural challenges. While the challenges I faced also are faced by domestic graduate students, a critical difference is that many more opportunities to obtain assistance that are availed to domestic students than to international students. For instance, domestic graduate students can qualify for financial aid and can also hold fulltime jobs to supplement their financial aid. One cannot do this as an international student.

While it is understandable that graduate school is designed for those who are academically competent, and that international students are expected to perform at the same level as domestic graduate students, my experience in adjusting to the rigorous readings and assignments in a doctoral program suggests that it would be helpful for international students if some form of adjustment support were available to facilitate their efforts to cope with their new learning environment. 


\section{CHAPTER V1}

\section{STUDY IMPLICATIONS DISCUSSION AND CONCLUSION}

\section{Introduction}

Implications for university administrators, professors, and foreign exchange counselors can be drawn from this study. It has been the objective of this study to gain knowledge that will assist foreign students in making the necessary adjustment to host institutions and cultures. I have limited my comments to discussion of challenges: academic, linguistic/social-cultural, interpersonal, financial, health/psychological and housing. Some of the implications may already be implemented in some departments; in that case, the implications can serve as a reference guide.

Implications for Professors

Professors have long been aware of the language difficulties and difficulties of adjusting to the new educational environment for international students. What many educators may not realize is that some students may fell negatively about their new learning environment if their individual needs are not addressed. In this study many students thought that professors had unrealistic expectations and recommended that professors be more approachable and helpful in the students' transition process. Although the majority of the students said that English was part of the college training on the survey; the majority of the focus group participants expressed their difficulties with the English language. Students felt that often 
professors are more concerned with completing the course requirements, quizzes and tests, than adjusting the current practices to students' needs and competencies. Professors and administrators need to consider putting accommodations in place for international students who may be struggling with the language and the new education system.

There is a general learning principle that if students understand the professor's expectation they will perform better and be more apt to look positively at their new learning experience. Some students were frustrated with all they had to do to adjust to the academic environment. This frustration could be alleviated by the professor taking time to explain to students the details of the course requirements. One student said that the graduate school handbook she was given was not comprehensive enough to help her with questions about her course requirements. She said that a more comprehensive graduate school handbook should be developed. This comprehensive handbook could explain details of graduate school academic requirements.

The whole graduate school experience needs to be looked at when orienting international graduate students. This study has emphasized on-going orientation. This can have an effect on the total adjustment process of students. A positive or negative experience during orientation could influence a student's attitude about learning and school in general. 
Implications for Internationalization Action Council and Diversity Action Council

Both internationalization Action Council and Diversity Action Council should be made aware of the international graduate school adjustment challenges. It is clear that undergraduate students come through in groups and there are handlers during orientation. Graduate students often arrive singly and thus don't get the same attention. There is needed to get this issue on the agenda of the President's Internationalization Action Council. International students pay extra money and this ought to result in more resources to support adjustment programs. There is also a need to bring together the Diversity Action Council and the Internationalization Action Council. This could be done as a one-day retreat to explore the recommendations offered in this study.

\section{Implications for International Affairs Counselors}

International affairs counselors should develop culturally responsive programs that are intentional, flexible and accessible to international graduate students. They should ensure that resource centers and their programs meet international graduate students' needs. This could be done by creating a culturally appropriate student outreach programs that involves international graduate student representatives in designing and evaluating these programs. The International Affairs Office could develop intercultural awareness among non-international students to help them learn how to guide their international student counterparts to the appropriate resources. Also, the office could develop a peer mentoring program and a resource center that can work as an information clearing house where students can meet 
mentors and peers, especially the senior international students. This could help students explore and validate their strengths, abilities, passions, values and special gifts, think through their priorities, and begin to form a clear picture of what they have to offer and what they would most like to do.

Implications for University Administration

It is clear from the students' responses that professors do not know how to relate to students who are having difficulties adjusting to the new learning environment, which is evidenced through students' complaints and frustrations. There is need to train and encourage professors to be approachable and to encourage students to utilize available advising, counseling and mentoring resources on campus. Students expressed their need for financial assistance. One of the recommendation is for the university to begin an international student scholarship fund to support students experience financial hardships, explore the efficiency of peer mentoring programs in other institutions to better understand the difference such programs can make, invest more resources in and give higher priority to improving training programs for international graduate students who work as teaching assistants, graduate assistants, and help in many capacities in their departments, develop ongoing policies and strategies to regularly obtain and analyze the student view point regarding needed programs, coordinate and better integrate the efforts by international student advisors, counselors and the international offices staff, with the goal of satisfying the student's needs for adjustment, and regularly convene the numerous university offices (e.g., 
International Affairs Office, Housing Office, Admissions, Health Services, Diversity and Internationalization Action Council), serving international graduate students to reduce duplication of services, to review students needs and university capacity to support student adjustment, and to reduce gaps in providing needed services to students.

\section{Conclusion}

This study concludes that the challenges international students encounter in adjusting to their new status as graduate students include unsatisfactory housing, inadequate financial resources, lack of culturally responsive programs that are intentional, flexible, and accessible, unfamiliarity with the America higher educational system, undeveloped infrastructure for on-going orientation programs, insufficient health services information, and unavailability of international graduate student mentoring programs. Some of these challenges appear to be inevitable, the result of moving from one academic environment to another. What can be done more efficiently, however, is to make clearer to these students what they can expect to find at the new university and to use whatever resources at the university's disposal to make sure that students succeed in their new status as graduate students.

In one sense, I have ended my investigation where I began. I started out with the conviction that international graduate students experience problems and difficulties in adjusting to their new status as graduate students. I felt that although the investigation focused specifically on only a small group of PSU student body- 
the international graduate students - it yielded results that can be applied broadly to PSU and to institutions beyond PSU.

My conviction along these lines has been strengthened. I feel that I have learned more about the nature of international graduate students' adjustment challenges and the extent of the problems encountered, and more about what can be done to alleviate them. 


\section{REFERENCES}

Agar, M. H. (1980). The professional stranger: An informal introduction to ethnography. Orlando, FL: Academic Press.

Babbie, E. (1989). The practice of social research (5th ed.). Belmont, CA: Wadsworth.

Bargar, R., \& Mayo-Chamberlain, J. (1983). Advisor and advisee issues in doctoral education. Journal of Higher Education, 54 (4), 407-432.

Bochner, S., Hutnik, N., \& Furnham, A. (1985). The friendship patterns of overseas and host students in an Oxford student residence. Journal of Social Psychology, 125, 689-694.

Bogdan, R. C., \& Biklen, S. K. (1992). Qualitative research for education: An introduction to theory and methods. Needman Heights, MA: Allyn \& Bacon.

Du Bois, C. D. (1956). Foreign students and higher education in the United States. Washington, DC: American Council on Education

Cieslak, E. C. (1955). The foreign student in American colleges: A survey and evaluation of administrative problems and practices. Detroit, MI: Wayne University Press.

Clarke, H. I., \& Ozawa M. (1970). The foreign student in the United States: with special reference to Martha (Naoko Ozawa). Madison, WIS: School of Social Work, University of Wisconsin. 
Committee on the College Student Group for the Advancement of Psychiatry (2000). Helping students adapt to graduate school: Making the grade. New York, NY: The Haworth Press.

Constantine, M. G. (2003). School counselors' ethnic tolerance attitudes and racism attitudes as predictors of their multicultural case conceptualization of an immigrant student. Journal of Counseling and Development, 81 (2), 18590.

Day, R., \& Hajj, F. (1986). Delivering counseling service to international students: The experience of the American University of Beirut. Journal of College Student Personnel, 7, 353-357.

Dillard, J., \& Chisolm, G. (1983). Counseling the international student in a multicultural context. Journal of College Student Personnel, 3, 101-105.

Glazier, J. D., \& Powell, R. R. (1992). Qualitative research in information management. Englewood, CO: Libraries Unlimited.

Glaser, B., \& Strauss, A. (1967. The discovery of grounded theory: Strategies for qualitative research. Chicago, IL: Aldine.

Goetz, J. P., \& LeCompte, M. D. (1984). Ethnography and qualitative design in educational research. Orlando, FL: Academic Press.

Hendersen, P., \& Forster, G. (1991). Groupwork. Cambridge, UK: National Extension College.

Idowu, A. (1985). Counseling Nigerian students in United States colleges and universities. Journal of Counseling and Development, 63 (8), 506-509. 
Johnson, V. D. (2003). Cultural group perceptions of racial climates in residence hall. NASPA Journal, 41 (1), 114-34.

Klineberg, D. \& Hull, W.F. (1979). At a foreign university: An international study of adaptation and coping. New York, NY: Praeger.

Komiya, N., \& Eells G. T. (2001). Predictors of attitudes toward seeking counseling among international students. Journal of College Counseling, 4 (2), 153-60.

Krueger, R. A., \& Casey M. A. (2000). Focus groups. A practical guide for applied research $\left(3^{\text {rd }}\right.$ ed).Thousand Oaks, CA: Sage

Lee, M. E., Abd-Ella, M., \& Burns, L. (1981). Needs of foreign students from developing nations at U.S. colleges and universities. Washington, DC: National Association of Foreign Student Affairs.

Locke, D.C., \& Velasco, J. (1987). Hospitality begins with the invitation: Counseling foreign students. Journal of Multicultural Counseling and Development, 7, 115-119.

Lofland, J., \& Lofland, L. H. (1995). Analyzing social settings. Guide to qualitative observation and analysis. Belmont, CA: Wadsworth Publishing.

Lysgaard, S. (1995). Adjustment in a foreign fociety: Norwegian Fulbright grantees visiting the United States. International Social Science Bulletin 7, 45-51.

Mallinkrodt, B., \& Leong, F. T. L. (1992). International graduate students, stress and social support. Journal of College Student Development, 33, 71-78. 
Manese, J.E., Sedlacek, W.E., and Leong, F.T.L. (1988). Needs and perceptions of female and male international undergraduate students. Journal of Multicultural Counseling and Development, 24-29.

Meloni, C. (1986). Adjustment problems of foreign students in U.S. colleges and universities. Washington, DC: ERIC Clearinghouse on Language and Linguistics.

McCraken, G. (1988). The long interview. Newbury Park, CA: Sage Publications. Miles, M. B., \& Huberman, A. M. (1994). Qualitative data analysis. An expanded sourcebook $\left(2^{\text {nd }}\right.$ ed. $)$. Thousand Oaks, CA: Sage.

Morgan, D. L. (1993) Successful Focus Groups: Advancing the State of the Art. Newbury Park, CA: Sage.

Pedersen, P. (1991). Counseling international students. The Counseling Psychologist, 19, 10-58.

Roxanna, M. S, Mark, K. W, \& Ju, Z. (2000). Issues of adjustment to higher education: International students perspectives. International Education, 30 (1), 17-35.

Sakurako, M. (2000). Addressing the Mental Health Concerns of International Students. Journal of Counseling and Development, 78 (2), 137-144.

Schram, J., \& Lauver, P. (1988). Alienation in international students. Journal of College Student Development, 29, 146-150.

Stake, R. (1995). The art of case research. Newbury Park, CA: Sage.

Surdam, J. C., \& Collins, J. R. (1984). Adaptation of international students: A cause for concern. Journal of College Student Personnel, 25, 240-244. 
Taft, R. (1977). Coping with unfamiliar cultures. In N. Warren (Ed.), Studies in cross-cultural psychology (pp.120-135). London, UK: Academic Press.

Tinto, V. (1993). Leaving college: Rethinking the causes and cures of student attrition (2nd ed.). Chicago, IL: The University of Chicago Press.

Vaux, A., Burda, P., \& Stewart, D. (1986). Orientation towards utilization of support resources. Journal of Community Psychology, 14, 159-170.

Wang, Y, (2004). Pursuing cross-cultural graduate education: A Multifaceted investigation. International Education, 33 (2) 52-72.

Weill, L. (1982). Advising international students at small colleges.

NACADA Journal, 2 (1), 52-56.

Yi, J. K., Jun-Chih. G. L., \& Yuko, K. (2003). Utilization of counseling services by international students. Journal of Instructional Psychology, 30 (4), 333-42.

Yin, R. (1994). Case study research: Design and methods (1st ed.). Beverly Hills, CA: Sage. 


\section{APPENDIX A}

\section{SURVEY QUESTIONNAIRE}

First of all, thank you in advance for participating! This survey is part of my dissertation. I am a PSU doctoral student doing a research study on the adjustment challenges of international graduate students. Your participation in this survey may help find a way to better satisfy primary needs of PSU international graduate students. It will take you approximately 15 minutes or less to fill out by checking any answers that may apply. If you feel uncomfortable answering some questions, please skip them. This survey is confidential and anonymous and your participation is voluntary. If you have concerns or problems about your participation in this study or your rights as a research subject, please contact the Human Subjects Research Review Committee, Office of Research and Sponsored Projects, 111 Cramer Hall, Portland State University, (503) 725-4488. I am available to answer any questions or concerns you may have about the study at: 503-760-6020or Vincent@pdx.edu:

A. Personal Information

1. Gender $\square$ Male $\square$ Female

2. Age:

3. Marital Status:

$\square$ Single $\square$ Married

4. Home Region

$\square$ Asia $\square$ Middle East $\square$ Africa $\square$ Latin America $\square$ Europe _ if unsure name your country of origin

B. School Information

5. Year you arrived at PSU to study:

6. What is your major?

7. What is your vocation objective? (e.g., engineering, law...)

8. Please check the box that represents the expected year of completion of your degree
$\square 2004$
$\square 2005$
$\square 2006$
$\square 2007$
$\square 2008$ 
$\square 2009 \square 2010$

9. When do you expect to return to your homeland?

$\square 2005 \square 2006 \quad \square 2007 \quad \square 2008 \quad \square 2009 \quad \square 2010 \quad \square 2011$

10. What is your GPA?

\section{General Information}

In the box on the right hand side of the listed items below, write a number that indicates how you agree or disagree with each listed item: (1) =strongly agree (5) =strongly disagree.

11. I learned about PSU from sources other than from PSU

12. The information I received during orientation was sufficient for my needs

13. There was an official agency that aided me on my arrival in Portland

14. English language was a part of my secondary or college studies

15. I acquired my conversational skills through school

16. My conversational skills are good enough to understand professors' lectures and instructions

17. Overall, my housing facilities are not adequate

18. In general, my health condition is good

19. I feel that the financial aid I'm receiving is sufficient for my needs

20. I have other sources of financial aid in addition to scholarship

21. I feel that I have sufficient time to do my study and my class assignments

22. In general I have been received on equal terms by American classmates

23. In general I think I have been received by people on campus

24. I participate in religious and other nonacademic activities

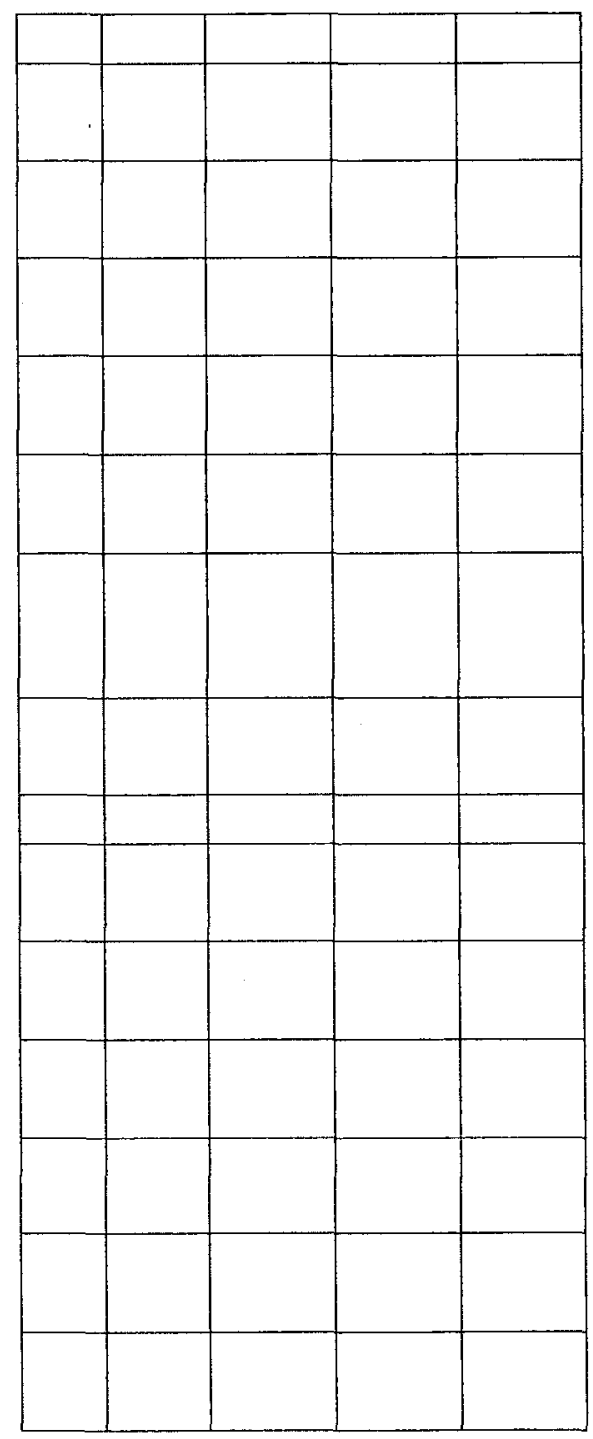




\section{APPENDIX B}

\section{IN-DEPTH INTERVIEW GUIDE}

1. Tell me about the orientation you received on your arrival at PSU. What was your being in a new environment like for you?

2. Describe your journey in graduate school to this point. How long have you been at PSU? What is your subject major area?

3. What do you see as key adjustment challenges of graduate school?

4. What information did you need on day one of class?

5. How has the information you received or did not receive impacted you?

6. Tell me a story about one stressful adjustment challenge you encountered at PSU?

7. What do you think is a better way to assist foreign students to achieve overall success at PSU?

8. Comments? 


\section{APPENDIX C}

\section{INFORMED CONSENT FORM}

You are invited to participate in a research study conducted by Vincent Womujuni from Portland State University, Department of Educational Policy Foundations, and Administrative Studies. The researcher hopes to learn about the challenges international students face in adjusting to their new status as a graduate student at Portland State University.

If you decide to participate, you will be asked to join in one focus group discussion which will last approximately one hour, and to complete a survey questionnaire which will take approximately 15 minutes. The researcher will be transcribing the tapes so that he will have an accurate record of your responses to his questions.

You may not receive any direct benefits from taking part in this study, but participation in the study may give you an opportunity to reflect upon your experience as an international graduate student at Portland State University. In addition, you will be provided the opportunity to comment upon the findings of the study should you wish to do so. The study may yield knowledge that may help others in the future.

Participants and the names of their schools/departments will remain confidential. All data collected will be coded to protect the participants in the study. Your participation in this study is purely voluntary. Your decision to participate or not will not affect your relationship with the researcher or others in any way. If you decide to take part in the study, you may choose to withdraw at any time without penalty. Please keep a copy of this letter for your records.

If you have concerns or problems about your participation in this study or your rights as a research subject, please contact the Human Subjects Research Review Committee, Office of Research and Sponsored Projects, 111 Cramer Hall, Portland State University, (503) 725-4488. I am available to answer any questions or concerns you may have about the study at: 503-653-5392 or you may write me at: 8366 SE Causey Ave. Apt\# 229, Portland, OR 97266.

Your signature indicates that you have read and understand the above information and agree to take part in this study. Please understand that you may withdraw your consent at any time without penalty, and that, by signing, you are not waiving any legal claims, rights or remedies. The researcher will provide you with a copy of this form for your records 
APPENDIX D

\section{FOCUS GROUP INTERVIEW PROTOCOL}

1. Describe your journey in graduate school to this point. Was there any agency or association that helped you on your arrival in Portland?

2. Are you any different because of the services you received?

3. Please tell me about any difficult, troublesome, or challenging situation that occurred to you on your arrival in the US or at PSU.

4. Think about the first day of class. What are the most important things you needed to get/listen to / watch for on day one?

5. How has the information you received or did not receive impacted you?

6. Suppose you were going to give advice to a new international student who comes from the same background as you. What specific advice would you give this student about what a student needs to know in order to succeed at PSU?

7. Suppose you were going to give advice to PSU administration about a better way to assist foreign students to achieve overall success, what specific advice would give?

8. Comments? 


\section{APPENDIX E}

\section{PILOT INTERVIEW QUESTIONS}

1. What services does the International Affairs Office provide to international graduate students?

2. How effective are these services in helping international graduate students achieve overall success in the degree programs?

3. How has the lack of English proficiency hindered students' adjustment?

4. Is there any collaborative effort between the Office of International Affairs and other academic and administrative departments supporting international graduate students' orientation at PSU?

5. What challenges do international graduate students encounter in transitioning to graduate school life?

6. Are there orientation programs specifically targeting international graduate students?

7. What difficulties, if any, has the International Affairs Office encountered in getting international graduate students to participate in the general orientation programs offered by PSU?

8. What has the office done to address those difficulties? 